\title{
El còmic i l'exili del 1939: des de la retirada fins a la diàspora i la resistència armada
}

\author{
Francisco Collado Cerveró \\ Universitat Politècnica de València (Espanya) \\ https://orcid.org/0000-0003-0704-3938
}

\author{
JOSEP-VICENT GARCIA RAFFI \\ CEDID - ELCiS - Universitat de València (Espanya) \\ https://orcid.org/0000-0001-5821-5221
}

Presentació: 15 feb. 2021 | Acceptació: 20 abr. 2021 | Publicació: 15 des. 2021

Citació recomanada: Collado Cerveró, Francisco; Josep-Vicent Garcia Raffi. 2021. «El còmic i l'exili del 1939: des de la retirada fins a la diàspora i la resistència armada». Dictatorships \& Democracies. Journal of History and Culture 9: 79-115. doi: https://dx.doi.org/10.7238/dd.voig.393448

Resum: En els còmics publicats a Espanya al llarg d'aquests darrers anys, es representa amb més freqüència la retirada de les tropes republicanes i de la població civil entre les acaballes del 1938 i els primers mesos del 1939. Títols com ara Los surcos del azar, Exilio, Las serpientes ciegas, El arte de volar, 'Winnipeg': el barco de Neruda, Un largo silencio i Deportado 4443 en són una bona mostra. El contingut temàtic dels volums que tractem — més de trenta - abraça, a més de la retirada al segon exili, la resistència armada a la dictadura des de fora i dins del país i els camps de concentració francesos i els d'extermini nazis. Oferim una panoràmica descriptiva i temàtica del nostre corpus d'obres amb algunes anotacions sobre els seus trets generals i el llenguatge graficoliterari que utilitzen. Paraules clau: còmic, exili, maquis, postguerra, resistència, retirada

\section{Comics and the 1939 Republican Exile: from La Retirada to Diaspora and Armed}

\section{Resistance}

Abstract: The representation of La Retirada, the retreat of Republican troops and civilians between the end of 1938 and the first months of 1939, has increased over the past few years in comic-books published in Spain. Titles such as Los surcos del azar, Exilio, Las serpientes ciegas, El arte de volar, 'Winnipeg': el barco de Neruda, Un largo silencio and Deportado 4443 are good examples of that. The thematic content of the comic-books analyzed - more than thirty — ranges over La Retirada and the second exile, the armed resistance to the Fascist dictatorship from the exile or from within Spain and the French and Nazi concentration camps. We offer a descriptive and thematic account of our body of works with some notes on their general features and their use of visual and literary devices.

Key words: comics, exile, Maquis, Spanish post-war, resistance, La Retirada 


\section{Introducció}

La literatura ha tractat àmpliament les conseqüències de l'exili republicà del 1939. A través de l'escriptura autobiogràfica i el dibuix, es recorden uns esdeveniments que marcaren la història contemporània. Hi ha dibuixos dels supervivents de la guerra, dels camps de concentració —el cas de Josep Bartolí és paradigmàtic - o de l'exili. Algunes vegades són dibuixos rudimentaris o esquemàtics dels tancats, dibuixos que intenten testimoniar, documentar.

També des del món del còmic — la historieta, el tebeo, la novella gràficas'han reflectit aquests fets i vivències. El còmic ha participat en la tradició gràfica del testimoniatge dels desastres causats per les guerres. El seu llenguatge, una mixtura entre imatge i text, és no només un instrument narratiu de primer ordre, sinó també una eina vàlida per a contar la història. Matly (2020, 40) explica — tot seguint Howell — que els còmics tenen una doble naturalesa, perquè són alhora relats d'història i objectes històrics, una font inestimable per als investigadors de ciències socials, historiadors, sociòlegs i psicòlegs per a entendre millor les mirades, sempre particulars i evolutives, que les societats projecten sobre el seu propi passat i sobre si mateixes. Quan el còmic pretén descriure fets històrics ha de comptar amb la informació que li ofereixen els historiadors, però la documentació ha de ser més completa:

Las memorias gráficas que nos proporciona la historieta no serían tan impactantes sin el substrato histórico del que se nutren. El aumento de novelas gráficas sobre la Guerra Civil debe mucho a la labor historiográfica, que hace que el conocimiento histórico hoy en día no sea el mismo que el de hace más de 40 años, recién fallecido el Dictador. En este sentido, los relatos han ganado en calidad y precisión, han mejorado los contenidos a medida que la historiografía marcaba puntos y divulgaba sus resultados. (Alary 2020, 354)

El relat memorial històric és un subgènere del còmic que va sorgir després de la publicació per entregues de Maus, d'Art Spiegelman (19801991). L’autor narra, mitjançant una representació zoomòrfica, la vida dels seus pares, jueus polonesos, víctimes de la Xoà. Posteriorment molts 
autors han compartit una memòria familiar o personal i han documentat molt curosament els seus àlbums amb un mètode semblant al de la historiografia.

Hazañas bélicas (1948) fou la sèrie popular de referència del còmic bèllic espanyol. S'hi narraven conflictes de la Primera i la Segona Guerra Mundial i de la Guerra de Corea, però no de la Guerra Civil, encara amb molt de pes en la vida dels pares i dels avis dels lectors. És a partir de la mort del dictador Francisco Franco quan el còmic espanyol ofereix una sèrie d'obres que han contribuït a la revisió de la memòria històrica pel que fa a la guerra del 1936 i les conseqüències de l'exili i de la repressió franquista. Això s'expressa en alguns casos com una crònica biogràfica:

El còmic d'autor és inconcebible sense una gran implicació personal. A diferència d'altres mitjans d'expressió, generalment el còmic l'elabora una persona o com a màxim un equip molt de reduït — dibuixant i guionista en la majoria dels casos-, de manera que el camí entre les idees i el producte final és molt directe. [...] Són incomptables els exemples en què els creadors i les creadores parlen de la seva pròpia memòria o de la seva memòria familiar. (Fernández de Arriba 2018, 48-49)

Michel Matly (2018, 2020), per a la seua investigació sobre el còmic, la Guerra Civil i les seues conseqüències, va seleccionar 250 títols d'un corpus encara major que incloïa tota classe d'historietes: l'àlbum independent i la tira o sèrie en una revista. S'ha editat en més de quinze països i en diverses llengües. Aquest tipus de còmic va aparéixer enmig de la contesa bèllica (en els dos bàndols), durant el franquisme i una vegada mort el dictador, el seu moment d'eclosió tant a Espanya com a l'estranger. Amb el triomf de la novella gràfica, basada sovint en la memòria, la història o el reportatge, els còmics testimonials s'han estès arreu.

L'exili, sense una producció gaire nombrosa, és vist amb una «doble mirada que evolucionarà segons les èpoques, del dolor de la separació als maltractaments als exiliats» (Matly 2018, 248). La producció és més actual, perquè el postfranquisme tarda a recuperar l'exili i, per tant, la narrativa gràfica l'inclou pràcticament al final del segle passat i sobretot en la primera dècada del segle XXI, que va suposar, amb algunes excepcions, 
un salt quantitatiu i qualitatiu. Els canvis editorials, estètics, comercials i fins i tot conceptuals que va tenir el còmic també afecten la guerra i l'exili (Alary 2016). La lectura del còmic sobre l'exili parteix de fonts fotogràfiques, de les quals s'extreuen imatges emblemàtiques, com les llargues files de la retirada o la del milicià invàlid travessant les carreteres nevades. L'autor crea els detalls de la vida quotidiana a mesura que va creant els personatges, que han de vestir, comportar-se, pensar i sentir com correspon a la seua època. Ha d'imaginar o reflectir una trama concreta en què es desenvolupin els protagonistes perquè puguem conéixer-los com a éssers humans i, al mateix temps, identifiquem el context social i polític que els condiciona.

Per a fer aquest estudi, hem agrupat cronològicament i temàticament en quatre grans ítems una selecció d'obres publicades en les llengües de l'Estat en els últims quaranta anys, concretament entre 1977 i 2020: la retirada o la fugida a l'exili, els camps de concentració, la diàspora d'ultramar i la resistència. Aquestes quatre categories són orientatives, perquè alguns dels títols poden enquadrar-se en més d'una.

Hem deixat de banda la interessant i rica producció sobre aquests nuclis temàtics que va apareixent en altres llengües europees, com ara l'italià -Futbolín, d'Alessio Spataro (2015) - , però també el francès, principalment, amb títols — alguns dels quals són traduïts a l'espanyolcom ara Les phalanges de l'ordre noir (1983), d'Enki Bilai i Pierre Christin; dins la sèrie d'Alack Sinner, Constancio et Manolo (1984), de José Muñoz i Carlos Sampayo; De Profundis 2: soudaine recrudescence (1997), de Claude Carré i Jean-Marie Michaud; Les parias (1997), de Louis la Guigne; Le convoi (2013), de D. Lapiére i E. Torrents; Exil (2013), d'Henri Faubel i Jean-Marie Mínguez, i molts altres àlbums sobre la resistència. ${ }^{1}$ I és que la «historieta francesa», com afirma Matly $(2018,206)$, «no duda en aventurarse por caminos esquivados o ignorados por la española de la misma época». Així doncs, «la violencia franquista, las luchas entre comunistas y anarquistas, los campos de concentración esperarán el cambio de siglo para ser evocados en España, mientras que aparecen mucho antes en el cómic francés».

1 Per a no allargar innecessàriament la bibliografia de còmics referenciats, no en fem la fitxa bibliogràfica. Hi hem consignat alguns títols a tall informatiu per al lector. 
Les relacions entre còmic i memòria són riques i diverses. Fernández de Arriba (2018, 50-53) n'estableix set formes en funció de l'enfocament del tema: l'autobiografia, la memòria directa, la memòria-ficció, la biografia, l'assaig històric i el còmic periodístic. Els còmics que comentarem podrien situar-se entre la majoria d'aquestes formes classificatòries. Nosaltres, però, triem una classificació cronològica i temàtica en la qual seleccionem alguns dels principals títols editats.

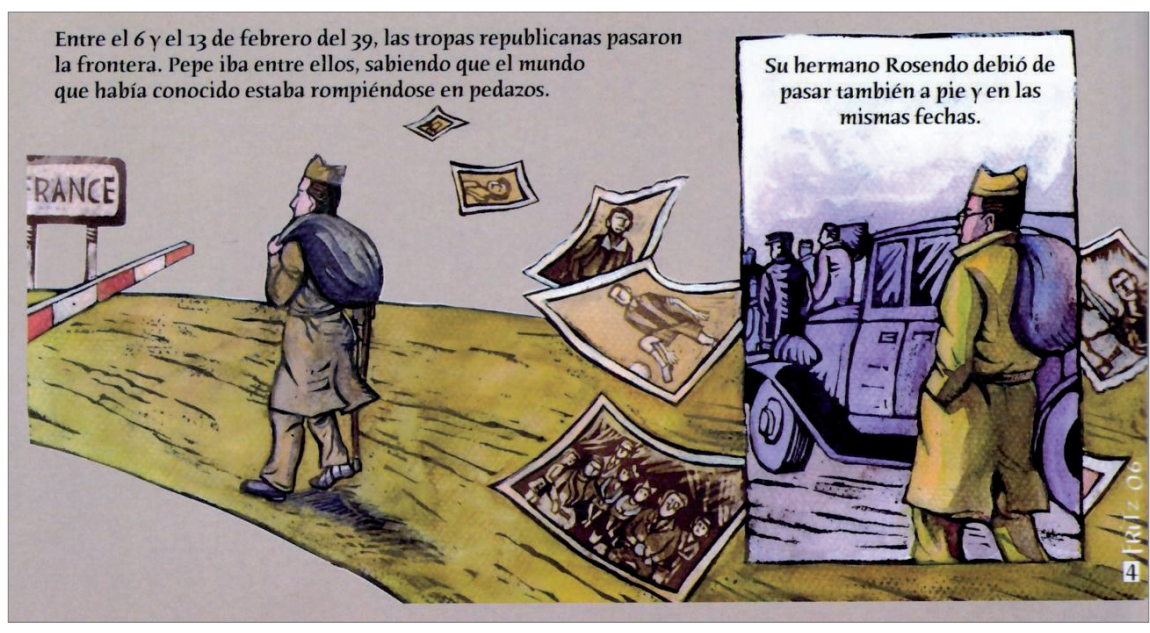

1 Mi tío, que estuvo en el infierno (Fritz 2006).

\section{La retirada i la fugida a l'exili}

El còmic que dibuixa l'exili, a banda de narrar violència, morts, patiment, nostàlgia i misèria, també retrata alguns dels grans valors humanístics, com ara l'amistat, l'amor, la solidaritat o la lleialtat. Hem seleccionat una desena d'àlbums ${ }^{2}$ per a estudiar aquest element temàtic. Alguns d'ells, a banda

2 Deixem fora d'aquest repàs els volums d'història d'Espanya contemporània o d'història de Catalunya que ofereixen vinyetes en l'interior o són en còmic i que dibuixen puntualment la retirada o els camps de concentració francesos i el primer exili. Són els casos d'Historia del socialismo español (1982), d’Octavio Cabezas, Manuel Berrocal i Juan C. Martín; Historia forgesporánea (1984), de Forges; La Guerra Civil en España, 1936-1939 (1987), de Jorge Alonso García; Nosaltres, els catalans, de F. Pérez Navarro i Jan (2008, 67); Història en historieta de Catalunya (1977), d’Avellí Artís-Gener Tísner; l'edició 
d'eixa fugida, també tracten la immediata entrada a camps de concentració en la primera etapa de l'exili, dels quals parlem amb més extensió en el segon grup. Com succeeix en les altres obres de ficció, s'usa la retirada o la retenció en els camps de concentració per a ràpidament (després de situar la història de forma sumària) contar la vida del personatge i els fets concrets posteriors. És el cas, per exemple, d'Esperaré siempre tu regreso (2016), de Jordi Peidro, ambientat en un camp nazi. En aquests còmics apareixen diversos camps de concentració francesos: el d'Argelers en Un largo silencio i El ángel de la retirada, ${ }^{3}$ el de Sant Cebrià en El arte de volar i el de Ribesaltes en Exilio, entre d'altres. Són un cas apart les dues obres amb personatges públics com a eix central del còmic: Picasso en la Guerra Civil (2018), de Daniel Torres, i Josep Irla. La lluita per un ideal (2007), de Quim Bou i Rafel Ponsatí. En el primer volum, les referències personals de Picasso conviuen amb les vivències passades i actuals dels republicans exiliats, a més d'una història dins la història dibuixada i ficcionada d'un Picasso combatent a la guerra. Pel que fa al segon volum, recorre resumidament la vida de Josep Irla, 124è president de la Generalitat de Catalunya, després de l'assassinat de Companys. S'hi relata breument la retirada des de Barcelona i l'exili francès.

gràfica d'Història de Catalunya. Dragui (1988-1989), de la qual el dissetè volum està dedicat a la Guerra Civil, la repressió i l'exili, o Història de Catalunya. De la prehistòria als nostres dies (2014), de Pilarín Bayés, Josep M. Solé i Queralt Solé. I també les planes finals de La Guerra Civil espanyola, amb guió de l'hispanista Paul Preston i dibuixos de José Pablo García, en què al novè capítol («Derrota a plazos») veiem reflectides a les vinyetes algunes de les fotografies més conegudes de la marxa, primer, de les Brigades Internacionals i, més tard, de la retirada de civils i soldats republicans, del pas per la frontera, dels camps francesos o del carboner Stanbrook, que va salpar des del port d'Alacant.

3 El ángel de la retirada és un àlbum traduit del francès, amb guió original de Serguei Dounovetz (escriptor i cineasta) i dibuixat per Paco Roca. La història es desenvolupa a la colònia espanyola de Besiers (primer formada arran de la immigració econòmica i després engrandida per l'exili), que celebra el seu 120è aniversari. S'hi planteja el tema de la identitat a través del personatge de Victoria, que pertany a la segona generació d'immigrants. Els nets dels espanyols poden sollicitar la nacionalitat espanyola. Això desperta el record del passat, la retrospecció de la història del camp de concentració d'Argelers. L'obra està dibuixada en bitó suau virat al blau i conté una epíleg final d'Anne-Marie Sabatier, que explica de bell nou l'element versemblant de la història dibuixada: «Si este cómic es una ficción, su contenido se basa sin embargo en hechos históricos que sucedieron hace ya algunas décadas» (Dounovetz \& Roca 2010, 57). 
Aquest àlbum sobre les memòries escrites del pare de Miguel Gallardo, Francisco, va obrir el camí que va permetre la publicació de les obres que analitzem (Fernández de Arriba 2018, 57). ${ }^{4}$ Empra la tècnica (que es veu, també, en la narrativa literària o memorialística) d'una coautoria familiar en temps històrics diferents: són les memòries d'un familiar editades i comentades per un altre familiar. Per tant, es presenta com un mosaic discursiu «que se realiza a través de la flexibilización del lenguaje» (Rodrigues 2020, 267). Va acompanyat de dibuixos, vinyetes i, finalment, de l'habitual paratext, que, en aquest cas, és un àlbum de fotos. Francisco Gallardo travessa tot el conflicte vinculat a la Guerra Civil i recorda la repressió primer als camps de concentració francesos i després a les presons franquistes. El còmic ofereix una visió més enllà dels límits de la historiografia. El factor humà de la narració està lligat als records familiars, i ha estat comparada amb Maus, de Spiegelman (Merino \& Tullis 2016, 219).

\section{Exilio (Kalvellido, Pujol \& Piera 2011)}

Lobra exemplifica el que significa el final de la guerra per als republicans: la retirada des de la ciutat de Barcelona fins als camps d'extermini nazi; una fugida a l'exili per a evitar la feroç repressió que el feixisme havia desfermat a les zones que anava ocupant. A través d'uns dibuixos desbordats de sentiment, s'hi expressa el reconeixement de la lluita de tots aquells homes i dones que van defensar allò que creien que era legítim: la República. Ells, que van perdre la guerra, no van deixar ni un moment endarrere la dignitat. Som davant d'una obra feta «con sentimientos y corazón» (Kalvellido, Pujol \& Piera, 2011,7).

4 L'obra de Gallardo va ser publicada sense gaire repercussió en un moment crític de l'edició del còmic espanyol. Amb el temps ha esdevingut un dels títols més citats i analitzats per estudiosos de diferents països quan parlen del còmic sobre la Guerra Civil i les seves conseqüències. És el cas, també, de Los surcos del azar, de Paco Roca; El arte de volar, d'Altarriba i Kim;36-39: malos tiempos, de Carlos Giménez, i la trilogia unificada en el volum Doctor Uriel, de Sento Llobell, estudiats en una bibliografia cada vegada més nombrosa. 


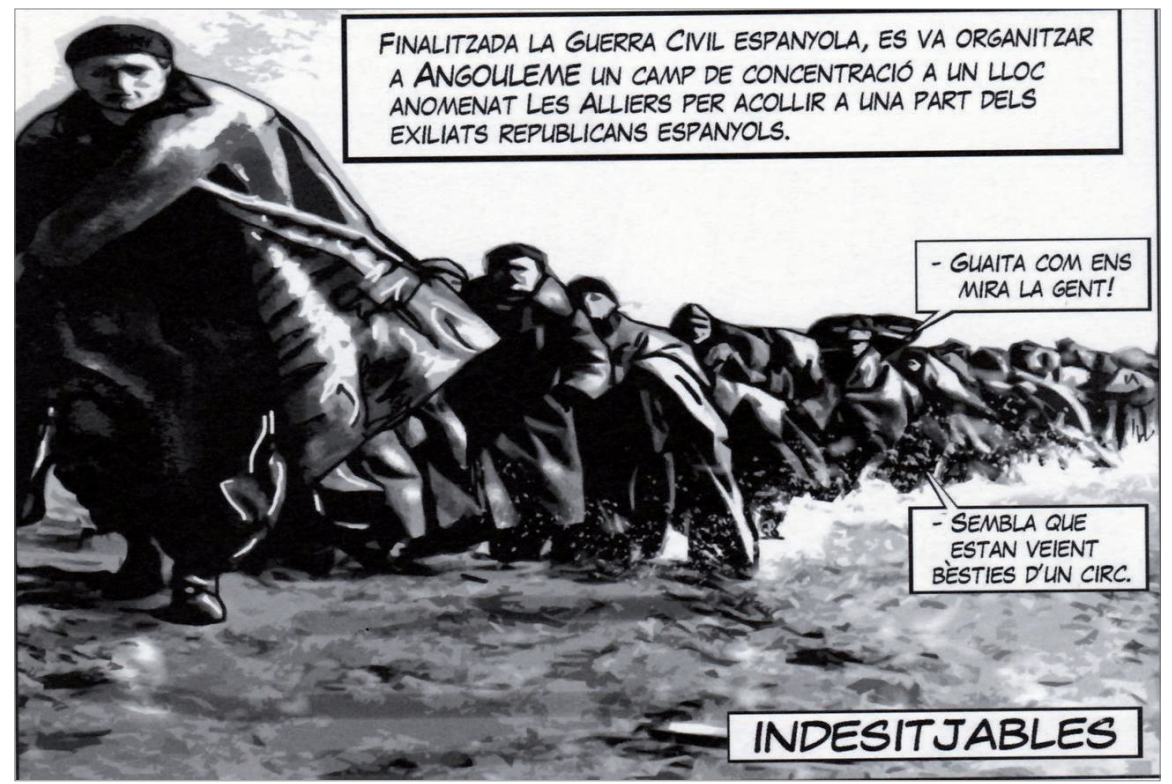

2 Exilio (Kalvellido, Pujol \& Piera 2011).

Los surcos del azar (Roca 2013)

Roca, que en la seua obra ha pouat en els diferents sentits de la memòria, parteix d'una investigació que el porta al descobriment d'un personatge verídic, que el narrador converteix en un protagonista complex amb dos noms i dues vides, almenys. És un jove anarquista que fuig d'Espanya en perdre la guerra i pateix totes les penalitats dels exiliats, participa en la Segona Guerra Mundial a Àfrica, a França i entra triomfal a París amb la Novena Divisió del general Leclerc per a caure, posteriorment, en l'abisme de la decepció i l'oblit. També recorda, però, la fugida dels darrers republicans des del port d'Alacant, amb el carboner Stanbrook, i la repressió als camps d'internament francès del desert d'Algèria. Hi ha un ús de la tècnica parallela i un diàleg dels personatges en temps històrics diferents. El relat se centra en les investigacions de l'autor, que entrevista el vell combatent republicà, que viu a França. També cal destacar les tècniques gràfiques utilitzades, lligades a la manera de contar o als continguts de la història; les vinyetes de l'investigador situades en un París 
actual són en bitò, mentre que les pàgines que relaten fets històrics són en color. Tanmateix, tal com assenyala Piedras Monroy (2017, 68): «Frente a la escritura "científica" y aséptica de la historia, la memoria inscrita en Los surcos del azar no apela solo a una borrosa verdad sino también al conocimiento que fluye a través de la experiencia y el sentimiento, por definición ajenos al relato histórico». Hi ha una edició més recent, del 2019, amb un increment de pàgines i paratextos que inclouen dos prefacis de les alcaldesses de Madrid i París. Una novella gràfica que ha esdevingut un clàssic del còmic contemporani.

\section{Las damas de la peste (Cosnava \& Del Rincón 2014)}

Imprés en bicolor (taronja i negre), narra amb gran fluïdesa gràfica la vida de tres dones molt diferents (Fe, Esperanza i Caridad), unides des de la revolució d'Astúries del 1934 fins al Maig del 68 a París. Després de participar en la revolució d'Astúries i en la Guerra Civil, fugen a França en camions que transporten el tresor artístic espanyol i que són bombardejats per l'aviació feixista. En travessar la frontera, els seus destins se separen i passen pels camps de concentració (Esperanza a Argelers), la dominació nazi i la integració al nou país en acabar la Segona Guerra Mundial fins a l'esclat estudiantil del 1968.

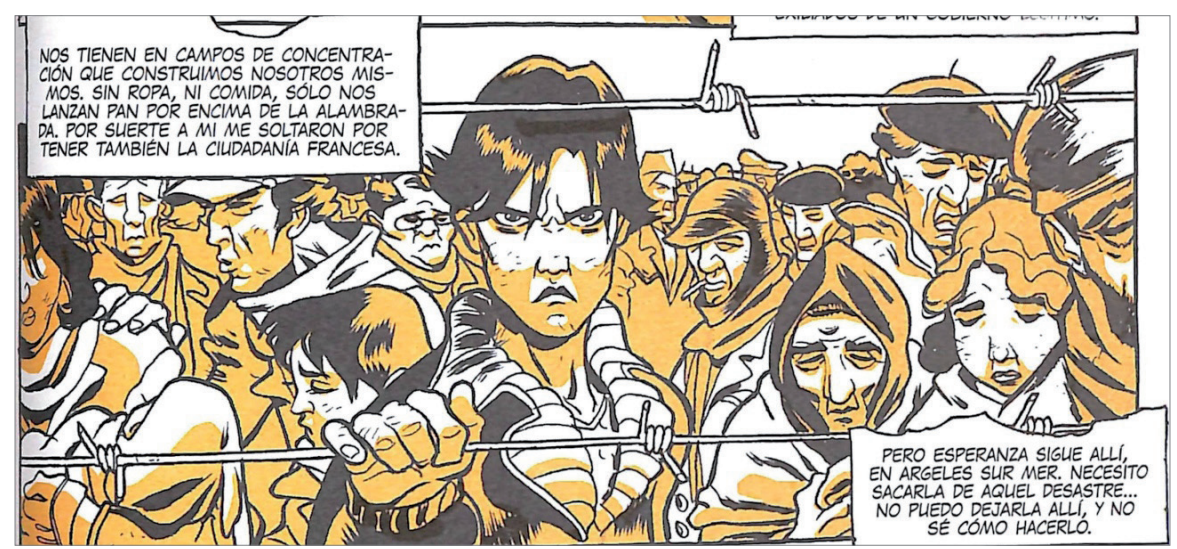

3 Las damas de la peste (Cosnava \& Del Rincón 2014). 


\section{El faro (Roca 2017)}

Narra l'arribada durant la caiguda de Catalunya d'un soldat republicà, inspirat en el soldat d'Almeria Francisco Valiente (és casualitat que compartisca cognom amb la protagonista d'El Ángel de la retirada), a un far del sud de França, on un home vell li torna la illusió de viure. El blanc i negre potencia el dramatisme de la realitat del derrotat i un cert to de fantasia onírica. En les pàgines finals, Roca (2014, 57-63) afegeix l'apartat «La eterna reescriptura», on explica tot el procés de diferents edicions i transformacions del seu treball.

Un dels símbols de l'exili espanyol, de la mort desarrelada, és Antonio Machado. Dos àlbums biogràfics expliquen el seu compromís republicà, la seua actitud envers la guerra i el seu exili i mort a Cotlliure: Antonio Machado. Los días azules (Hill \& Salvia 2019) i Ligero de equipaje: Vida de Antonio Machado (2019), que és l'adaptació d'una biografia anterior de l'historiador Ian Gibson, amb dibuixos de Quique Palomo. ${ }^{5}$

En tots els còmics que acabem de mencionar l'element cronològic que emmarca els fets, el període entre el desembre del 1938 i el febrer del 1939, posseeix una gran càrrega simbòlica que ens permet parlar d'aquest fenomen amb un identificador que la historiografia utilitza habitualment: la retirada del 39. Hi ha altres obres que tenen de vegades una o diverses vinyetes que sintetitzen aquesta retirada com a final de la guerra. És el cas de 1936: memòria d’un estiu, de M. A. Bergès i Josep M. Cazares $(2006,55)$.

Quan els còmics expliquen la història d'un personatge (no espanyol) implicat en les lluites que s'han desenvolupat al segle xx, el més habitual és que entre els seus compromisos haja estat el suport a la Segona República espanyola, el combat contra el feixisme i l'exili amb republicans espanyols. En citarem dos casos: el de Tina Modotti i el de Simón Radowitzky. Tina Modotti, italiana emigrada als EUA, feminista, activista, fotògrafa, actriu i brigadista internacional, és explicada i dibuixada per Ángel de la Calle en Modotti. Una mujer del siglo XX (2019), i inclou la seua participació en la

5 La mort i la tomba d'Antonio Machado a Cotlliure ha esdevingut un motiu literari per a simbolitzar la derrota i l'exili dels republicans. Apareix, per tant, a altres còmics, com ara Los surcos del azar, de Paco Roca (2013, 63-65); Exilio, de Kalvellido (2011, 17), i Modotti. Una mujer del siglo xx, d’Ángel de la Calle (2019, 238) 
Guerra Civil, la retirada i el seu viatge fins a Mèxic. El text presenta diverses polifonies amb fragments de textos de César Vallejo i Antonio Machado, que avancen en cada plana sobre elements del Guernica de Picasso. 155. Simón Radowitzky (2016), de Comotto, narra la vida d'un dels presos més importants del segle $\mathrm{xx}$, un anarquista condemnat per la repressió i la presó durant dècades que combatrà al front d'Aragó en la Guerra Civil i que des dels camps de concentració francesos viatjarà finalment a Mèxic.

Un cas remarcable de com el còmic pot relacionar situacions anàlogues d'exili en diferents èpoques i cultures és el d'Asylum (2017), de Javier de Isusi. Marina, de noranta-quatre anys, recorda des de la residència on viu tot el seu camí d'exili des d'Euskadi fins a Veneçuela. Aquesta experiència emmarca i s'entrecreua amb quatre persones més exiliades en la societat actual: Sanza, Aina, Cris i Imelda fugen cadascuna de la guerra i la violència, dels matrimonis a la força, de l'explotació sexual, de l'homofòbia i del feminicidi.

\section{Camps de concentració i d'extermini nazi}

Pel que fa als còmics que parlen dels camps de concentració francesos, ho fan d'una manera temàticament parcial com a conseqüència de la retirada i en l'explicació del principi de l'exili dels republicans. Quan els retraten, apareixen elements temàtics que expliquen la situació real dels republicans: l'arena de les platges on els van confinar, la mar gelada, el fred hivernal, la xabola de mantes o la barraca de fusta, la manca d'higiene, les malalties que els consumien (tifus, disenteria, etc.), l'alimentació escassa, el maltractament, la vigilància (guàrdia mòbil, senegalesos, etc.), els cercles de solidaritat entre amics i companys, la frustració de la derrota, el somni d'un possible retorn i la sortida dels camps, les repatriacions a l'Espanya franquista, etc.

La guerra havia acabat, la derrota s'havia consumat i milers d'exiliats sobrevivien als camps de concentració francesos a les portes de la Segona Guerra Mundial. Trobem referències d'Argelers (Un largo silencio, El ángel de la retirada, Las damas de la peste, El convoy, El artefacto perverso), el Barcarès (Un largo silencio, Esperaré siempre tu regreso), Vernet (Frontera de Ordesa, Deportado 4443), Ribesaltes (Exilio), Gurs (¡Animales de campo! 
El sufrimiento de los presos republicanos en Francia) o Sant Cebrià (El arte de volar, 155. Simón Radowtzky). També hi apareixen els camps nordafricans, com Morand, prop de Boukhari, a Algèria, o els treballs forçats a les obres del ferrocarril transsaharià (Los surcos del azar). Alguns d'ells ja els hem comentat en l'apartat anterior i no entrarem a detallar-los ara. ${ }^{6}$

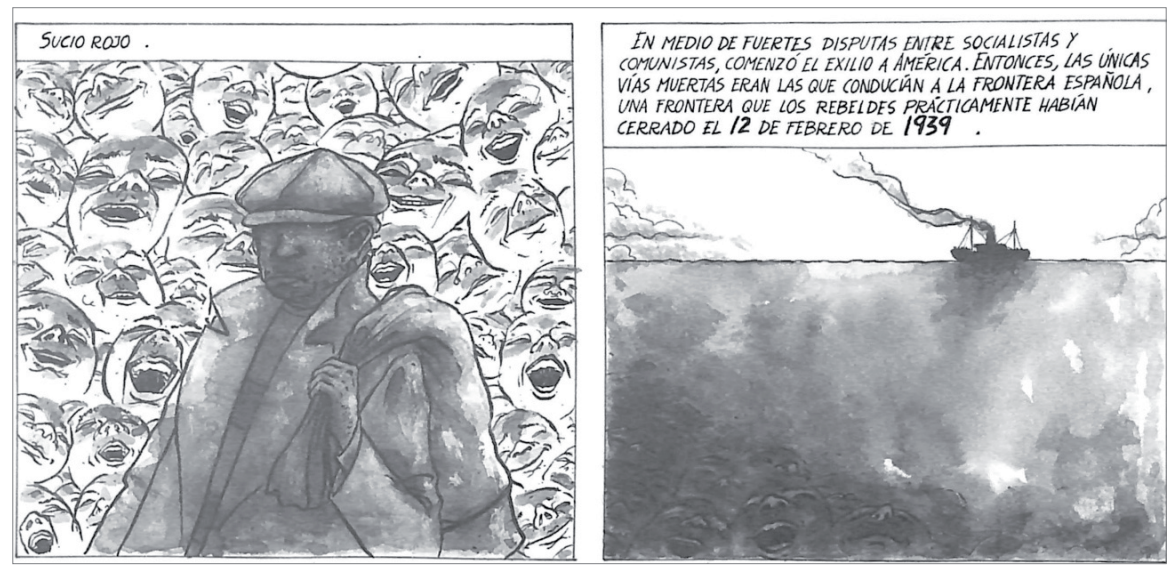

4 Vías muertas (García \& Díez 2003).

¡Animales de campo! El sufrimiento de los presos republicanos en Francia (Migoya, Fuster \& Acuña 2011)

És el catorzè volum de «Nuevas Hazañas Bélicas», una collecció d'historietes creada pel guionista Hernán Migoya. Homenatja les clàssiques Hazañas Bélicas (1948), de Boixcar. Aquest quadern de la «Serie Roja»7 ens porta el patiment dels refugiats als camps francesos basantse en el testimoni del pare del dibuixant Miguel Fuster, Luís, camperol aragonès, al camp de Gurs.

6 Tot i que comentem àlbums complets, no deixarem d'anotar-hi historietes com ara «Vías muertas», amb guió de Jorge García i dibuixos de Miguel A. Díez, en la revista Dos veces breve, d'Ariadna Editorial. El protagonista passa de les guerres d'Àfrica a la Guerra Civil i després fuig com a refugiat a França i s'exilia definitivament a Mèxic. Els raïls de tren són eixes vies mortes que, com a leitmotiv, el transporten durant el seu periple vital, carregat de decepció i desesperança. També en el volum collectiu Nuestra Guerra Civil trobem una història curta «Mi tío, que estuvo en el infierno» (2006), de Fritz, sobre un pres de Mauthausen.

7 De la mateixa sèrie, al volum Dos águilas de un tiro apareixen els camps francesos i la participació dels republicans exiliats en la resistència contra el nazisme. 


\section{El artefacto perverso (Hernández Cava \& Del Barrio 1996)}

Una obra ben valorada i premiada per la crítica com una «recreación y transformación magistral, tanto en lo documental y narrativo como en la investigación magistral, tanto en lo documental y narrativo como en la investigación gráfica, del ambiente del Madrid de la postguerra» (Alsina 2002, 210). S'hi narra com sobreviu un dibuixant de tebeos, excombatent $\mathrm{i}$ mestre republicà represaliat que havia escapat a l'exili, patint les condicions dels camps de concentració francesos i lluitant als maquis i la resistència. La trama fa que es retrobe amb els seus companys i les pors del passat, on l'alt contrast de blancs i negres i les transformacions fantàstiques dels rostres d'alguns dels personatges creen una atmosfera d'opressió, tensió i temor. Alary (2020) descriu l'obra en aquests termes:

[...] S’appuie sur une écriture de genre : le policier, le roman noir. Il nous immerge dans l'après-guerre, dans un clair-obscur épuré. Il n'y a pas de voix narrative. Toute la violence de ce temps sépulcral est suggérée plus qu'exprimée par le dialogue et l'image, par la contiguïté des cases et des planches, créatrices d'atmosphères comparables aux atmosphères des romans de Muñoz Molina ou de Juan Marsé.

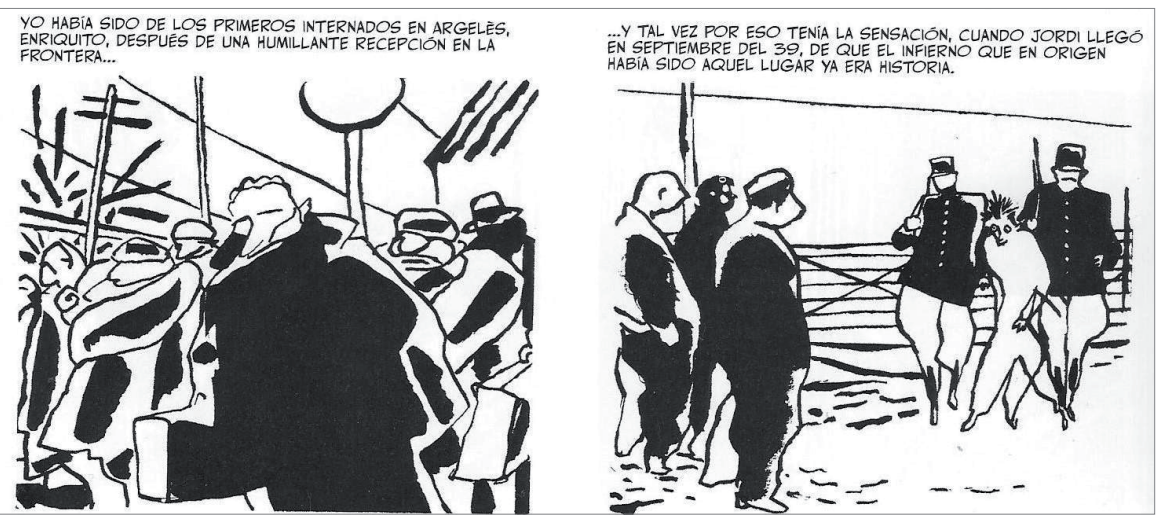

5 El artefacto perverso (Hernández Cava \& Del Barrio 1996). 


\section{El arte de volar (Altarriba \& Kim 2009)}

Novella gràfica amb un dibuix gris, detallista, potent, realitzat amb la tècnica de l'aiguada (barreja d'aigua i tinta). Kim illustra el guió escrit per Altarriba sobre la vida i el suïcidi del seu pare, que havia estat tancat al camp de Sant Cebrià. Hi ha una sensació de mosaic narratiu en l'organització gràfica dels capítols; així, «la representación de la caída del personaje desde la cuarta planta hasta chocarse contra el suelo, el paso que organiza cronológicamente el tiempo narrativo, metaforiza los retazos de la existencia humana cuyas memorias también son fragmentarias» (Rodrigues 2020, 271). A partir de la seua dura vida, es repassen els esdeveniments que van afectar la majoria de la societat espanyola en el convuls segle xx: «El doloroso componente sentimental de la memoria de Altarriba se mezcla así con una visión intelectualmente objetiva de lo ocurrido» (Alcantarilla 2017, 49). El còmic ressegueix la infància, la guerra i l'exili del personatge, passant per les seves estades a presons i camps de concentració, fins que s'uneix a la resistència francesa, amb els maquisards, quan es retroba amb un company de la guerra a Espanya. Després de lluitar durant dos anys decideix abandonar, fastiguejat, una lluita que reconeix que mai no va fer completament seua.
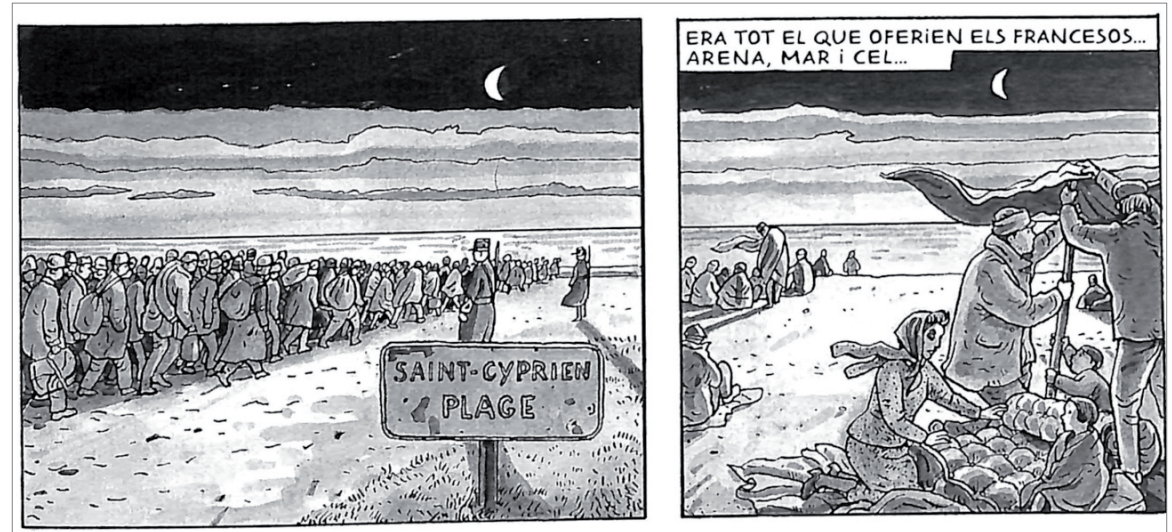

6 El arte de volar (Altarriba \& Kim 2009). 
En alguns casos, els còmics que inclouen com a nucli temàtic la reclusió als camps se centren en els d'extermini nazi. El que més protagonisme té és el de Mauthausen-Gusen, que apareix com a escenari de tots cinc còmics seleccionats a continuació. No és casualitat, perquè, dels 9.00o deportats espanyols, uns 7.200 acabaren en eixos camps i 4.800 hi moriren. Tanmateix, també es fa menció del camp de Ravensbrück, majoritàriament destinat a dones, i d'altres Stalags nazis durant l'ocupació de França.

\section{Un buen hombre (Cosnava 2009)}

Volum amb diverses històries curtes però relacionades entre si, embastades pel guió de Javier Cosnava i dibuixades per deu autors diferents. Lacció està situada en una urbanització — siedlung o ciutat jardí— propera al camp de Mauthausen i, en almenys tres, els protagonistes són republicans espanyols internats. Una entrevista — possiblement fictícia- amb Marie Wiegmann, una supervivent, dona pas als fets i als comportaments d'oficials nazis analfabets i totalment manipulats, que assumeixen la crueltat, el masclisme, el sadisme i la mort com a ingredients naturals de la seua quotidianitat. I tot això quan ja s'albira la derrota del Tercer Reich, sota l'ombra del Faust de Goethe, amb Mefistòfil.

\section{Esperaré siempre tu regreso (Peidro 2016)}

Empra una estructura comparativa, tècnica narrativa que ja hem vist, entre una situació contemporània - els camps de concentració dels Balcans - i el tancament als camps d'extermini nazi. La situació als Balcans dels anys noranta és el punt de retrospecció d'un personatge que els paratextos identificaran com a Francisco Aura Boronat, deportat a Mauthausen, paratextos reforçats pel testimoni dels seus fills, pel de dos historiadors, per una bibliografia i per una videografia. Làlbum està dividit en capítols curts de títol temàtic, amb una estructura circular que ofereix diferents expressions gràfiques: informacions històriques dibuixades en format de notícia de diari o les tires còmiques de «Las aventuras de Serranito Suñer». 


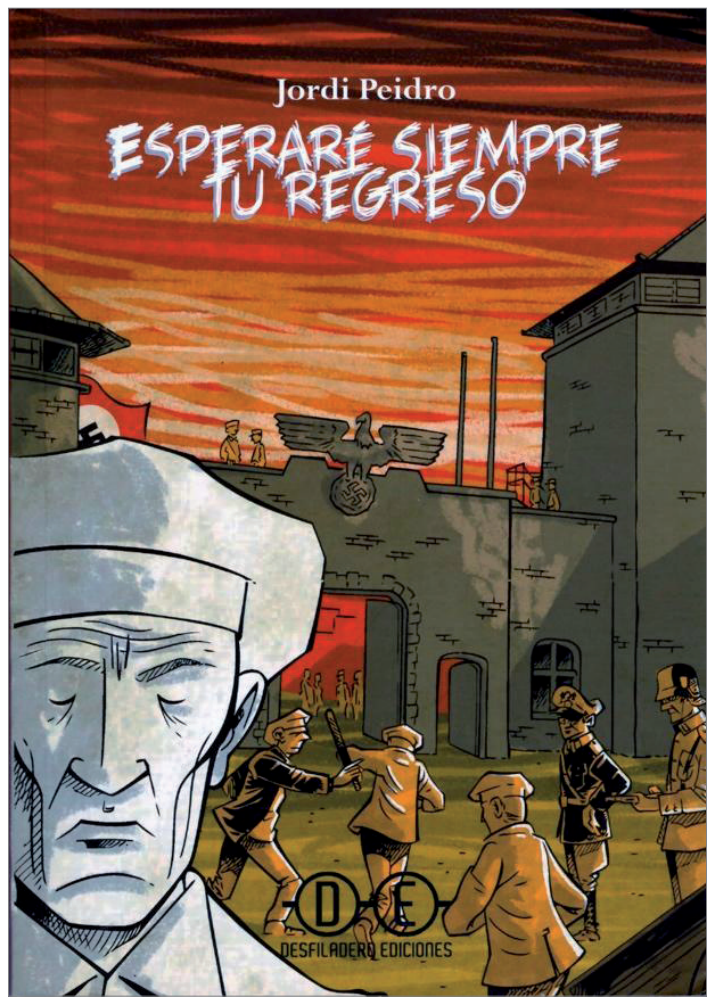

7 Esperaré siempre tu regreso (Peidro 2016).

\section{El fotógrafo de Mauthausen (Colombo, Rubio \& Landa 2018)}

Bàsicament és un biopic de Francesc Boix. Com és habitual, els paratextos remarquen la versemblança històrica, en aquest cas, amb un «dossier histórico» (Rubio 2018, 111-163) complet i escrit per especialistes. D’altra banda, com a argument d'autoritat l'historiador i guionista, Salva Rubio $(2018,[5])$, escriu el següent en una nota a peu de pàgina de la introducció:

El guión fue revisado por Gregor Holzinger y Ralf Lechner (Archiv. Der $\mathrm{Kz}$ Ceden Kstäte Mauthausen), Margarida Sala (Museu d'Història de Catalunya) y Rosa Toran (Amical de Mauthausen y otros campos), les estoy profundamente agradecido. Sus consejos y correcciones fueron tenidos en cuenta (excepto en aquellos lugares donde la adaptación de los hechos fue necesaria). 
Som davant un còmic que reconstrueix el procés d'ocultació i eixida de les fotos que feren un oficial nazi i Boix al camp. Hi ha una potent reflexió política: des de l'organització comunista al camp a la frustració pel no acabament del franquisme tot i haver finalitzat la Segona Guerra Mundial. A més, Boix critica el judici de Nuremberg i l'actitud de l'aparell comunista cap als deportats.

\section{Prisionero en Mauthausen (Carbos \& Cosnava 2011)}

Obra inspirada en esdeveniments reals ocorreguts al camp de Mauthausen. Els nazis que la coprotagonitzen existiren, però no el personatge principal, Juan Placambó, que és fictici. En les primeres pàgines apareix un poeta famós, Miguel Hernando [sic], escapat de la presó d'Alacant i traït i assassinat per Placambó. Hi ha una reconstrucció de mapes, de cartes i un fals estudi racial que fa un membre de la Gestapo, Paul Winzer, en què els republicans espanyols són tractats de subhumans. Les vinyetes s'intercalen amb l'epistolari fictici entre Winzer i Faust Dietrich Zur Linde, comandant del camp.

\section{Deportado 4443 (Hernández de Miguel \& Ensis 2017)}

Aquest àlbum és fruit d'una textualitat diversa prèvia: el periodista Carlos Hernández de Miguel va investigar sobre els deportats republicans als camps nazis (entre ells hi havia un oncle seu). En 2015 va convertir aquesta informació en desenes de piulades que van convocar gairebé 50.000 tuitaires. D’aquelles piulades Ensis va crear-ne aquesta obra; per això té el subtítol de Sus tuits ilustrados. El volum presenta dibuixos en blanc i negre de format gran, propers a la fotografia documental i que recorden els testimonis gràfics que han quedat dels camps d'extermini.

\section{L'exili mar enllà}

L'avanç franquista al front nord durant la Guerra Civil va comportar l'evacuació de milers de xiquets entre el març i el juny del 1937. A les acaballes del 1938 i els primers mesos del 1939, per tal d'evitar la feroç 
repressió que el feixisme havia desfermat a les zones que anava ocupant, es va produir la retirada majoritària de les tropes republicanes i la fugida a l'exili de milers de persones de la població civil. La fugida marítima es va fer amb tota classe d'embarcacions. Entre 1937 i 1943 s'han documentat 268 vaixells que transportaven republicans. Les rutes acabaven als ports d'Àfrica, Amèrica o Europa. ${ }^{8}$

'Mexique': el nombre del barco (Ferrada \& Penyas 2017) i 1937: los niños de la guerra (Jiménez, Cascajo \& Pedrosa 2018) s'avancen dos anys a la retirada i al gruix de l'exili del 1939 i representen els exilis d'aquells que fugen de la guerra en els moments incerts, durant els quals se n'ignora el desenllaç final. A més, tracten particularment l'èxode dels més petits, dels refugiats que, amb la seua infantesa trencada, van salvar la vida però que, a canvi, en molts casos van perdre la família i la identitat.

\section{'Mexique': el nombre del barco (Ferrada \& Penyas 2017)}

Aquesta mixtura entre còmic i llibre illustrat narra el viatge del vaixell Mexique amb 456 xiquets espanyols, fills i filles de republicans, que va salpar des de Trompeloup, prop de Bordeus, el 27 de maig de 1937, fins a arribar el 7 de juny del mateix any al port mexicà de Veracruz. D’allí, els xiquets van ser traslladats a Morelia, capital de l'estat de Michoacán. Allò que semblava que seria una aventura o unes vacances de pocs mesos esdevingué un exili permanent. El llibre, carregat alhora de lirisme i de dramatisme, està organitzat en imatges en blanc i negre, en les quals el roig s'insereix com a espurna de vida: es fa present en les galtes de xiquets i xiquetes de cames rosades, en algun vestit que trenca l'àmplia escala

8 Deixem de banda Sol poniente (2015), de Joaquín López Cruces i María Isabel Santisteban, que tracta molt subtilment l'exili a França i el trasllat d'una part de la família protagonista als EUA. També podem llegir «Noches de agua» (Hernández, Del Barrio \& Fernández 1991), un relat curt a tot color dins del volum Los derechos del niño (1991). Fa referència a l'article 38 de la Declaració dels Drets del Xiquets sobre dret internacional humanitari en conflictes armats. Com el còmic anterior, ens conta la partida del vaixell Habana des de Santurtzi amb una parella de germans bascos, Amaia i Txomin, evacuats. En arribar a territori francès, embarquen en un altre vaixell que els duu fins a Leningrad (URSS), on són separats i comencen a integrar-se en la vida del país d'acollida. D’altra banda, cal destacar el viatge frustrat amb l'Stanbrook que narra la historieta curta Fuegos del fin del mundo, amb guió de Jorge García i dibuix de Miguel A. Díez. 
de grisos, en el fum de la xemeneia del vaixell. Tanmateix, l'escala tonal preponderant ens remet a les conseqüències de la guerra, de la fugida, de com esdevingueren exiliats permanents sense pàtria, sense família i, el que és més difícil de pair, sense saber realment d'on eren.

\section{7: los niños de la guerra (Jiménez, Cascajo \& Pedrosa 2018)}

Forma part de la sèrie «Universo 1936», una collecció de tebeos que reflecteix alguns dels moments més significatius al voltant de la Guerra Civil. És un relat curt que conta la història des del punt de vista d'una xiqueta evacuada, Arantxa, barrejant el relat intimista, la història i el relat de ficció amb personatges amb superpoders. Els xiquets embarquen el 13 de juny des del port de Santurtzi al vapor Habana, rumb al port francès de Pauillac, on, sense desembarcar, una part dels infants van ser transbordats a un altre vaixell rumb a la Unió Soviètica.

Recuerdo que era de noche y que el puerto de anturce estaba lleno".

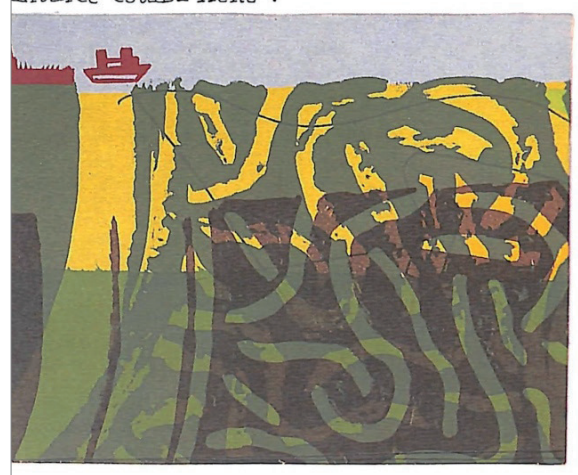

"Y que el barco se llamaba Habana, que es la ca pital de Cuba".

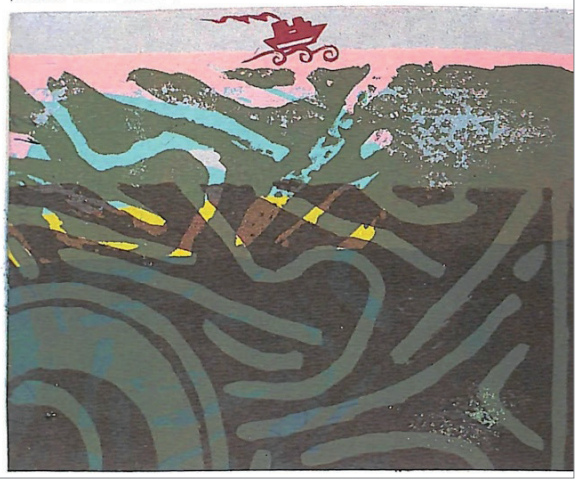

8 «Noches de agua» (Hernández, Del Barrio \& Fernández 1991).

\section{'Winnipeg': el barco de Neruda (Martel \& Santolaya 2014)}

Conta, a través dels protagonistes Manuel i Júlia, pare i filla, l'escapada a França, el pas pels camps de concentració i per orfenats i, per fi, el viatge cap a Amèrica. L'any 1939 el poeta Pablo Neruda, aleshores ambaixador de Xile a França, va aconseguir reunir els fons necessaris per a noliejar un vaixell cap 
al seu país, prèvia selecció, amb més de 2.200 exiliats republicans espanyols. Salpà del port de Trompeloup el 4 d'agost de 1939 i va arribar el 3 de setembre a Valparaíso. Martel arma el relat, d'estructura senzilla, reconstruint part de les vivències de Roser Bru (Barcelona, 1923), pintora i gravadora resident a Xile, i d'altres passatgers del Winnipeg, recorrent a documentació diversa que la illustradora plasma en vinyetes. Com en 'Mexique', el dibuix i la tonalitat emmarquen en blanc i negre, amb la tècnica del llapis i el carbonet, unes vinyetes que ofereixen un treball que sembla inacabat.

Quan de tu s'allunya. De l'ocupació de París a la caça de bruixes (Juste de Nin 2015)

Narra el llarg viatge d'un grup de catalans exiliats a París que volen fugir a Amèrica quan França és ocupada pels nazis. Després d'alguns intents infructuosos, per fi salpen des de Marsella cap a Orà; d'allí viatgen en tren fins al Marroc i de nou van en vaixell a Portugal, Mèxic i, finalment, Nova York. L'obra repassa els esdeveniments parallels a la Segona Guerra Mundial i s'allarga cronològicament mostrant-nos la nova vida als Estats Units, la caça de bruixes, el racisme o la vida cultural fins al 1957. La parella protagonista està formada pels periodistes Mariona Bosch i Pep Pubill, però s'hi presenta una extensa galeria de personatges reals (escriptors, cartellistes, polítics, periodistes, músics, actrius, etc.), principalment de l'exili català.

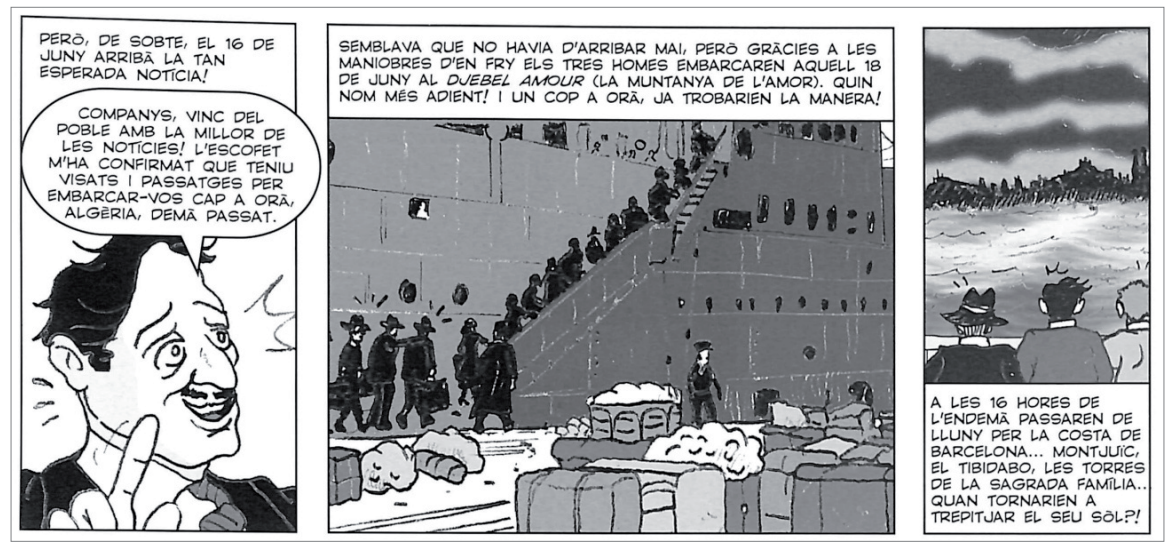

9 Quan de tu s'allunya. De l'ocupació de París a la caça de bruixes (Juste de Nin 2015). 
'Mexique': el nombre del barco, 1937: los niños de la guerra, 'Winnipeg': el barco de Neruda i Quan de tu s'allunya. De l'ocupació de París a la caça de bruixes comparteixen una sèrie d'ítems descriptius: la percepció de la derrota i la conseqüència posterior amb la retirada, tot passant per la supervivència als camps de concentració i el viatge (gràcies a la solidaritat internacional) cap a un futur esperançador allunyat geogràficament, que en els casos dels exiliats infantils esdevindrà permanent.

\section{Las serpientes ciegas (Hernández Cava \& Seguí 2008)}

La trama principal se situa en l'estiu del 1939. Està dividit en set capítols, en els quals el passat i el present se superposen, com també els escenaris (des dels baixos fons de Nova York a les trinxeres de la batalla de l'Ebre i la Barcelona de la Guerra Civil) i les vides dels protagonistes principals, amb caràcters i perfils contraposats però tots amb un passat tèrbol. És una obra de gènere negre que barreja el suspens amb un rerefons històric i que reflecteix la violència, els ajustos de comptes, les traïcions i les venjances de la guerra i de l'exili. En el fons, tracta de les misèries humanes i dels extremismes ideològics amb un punt de profunda decepció. El color i el dibuix de la història adopten tonalitats fosques que busquen atmosferes obscures i, en certa mesura, tenebroses i, de nou, el vermell és el contrapunt càlid d'una paleta basada en les ombres.

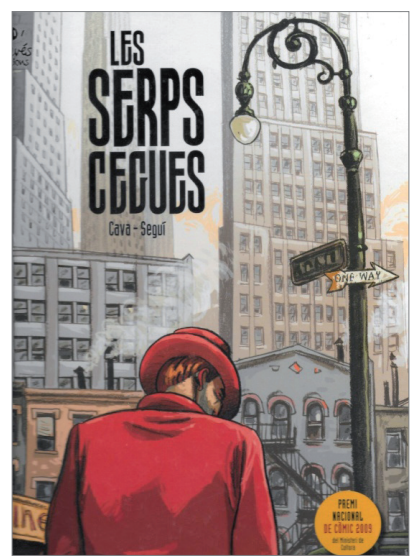

10 Las serpientes ciegas

(Hernández Cava \& Seguí 2008). 


\section{Blanquito (Ávila \& Viñuales 2013)}

Guió basat en els textos del llibre de relats autobiogràfics homònim de Mariano Viñuales, publicat a Mèxic l'any 1943. Són tretze contes - situats a la colònia del Llano - emmarcats per la narració de la retirada, el viatge amb el vaixell Flandre a la República Dominicana i l'escriptura dels contes a Ciutat de Mèxic. Les vinyetes presenten uns peus que concentren la major part dels textos de Viñuales. Hi surten tota una sèrie de personatges que treballen amb el protagonista: Cunita, Cilico, Andresito, Blanquito... Hi ha una meditació des del tròpic del que ha viscut el narrador a la guerra i a l'exili.

Com hem assenyalat adés, hi ha categories temàtiques compartides per diferents títols, i això passa, en aquest cas, amb altres títols que inclouen els viatges d'ultramar dels exiliats. N'és un exemple Los surcos del azar, en què es retrata l'experiència del viatge dels exiliats que embarcaren al carboner Stanbrook des del port d'Alacant fins a Orà, i d'aquí als camps de concentració del nord d’Àfrica. El còmic 155. Simón Radowitzky narra el viatge cap a l'exili mexicà del protagonista, el qual representa la imatge d'un lluitador internacionalista que fa seus tots els països on lluita per un món millor i dels quals, precisament per això, ha de fugir: Rússia, Argentina, Espanya o França. També a Modotti. Una mujer del siglo xx la protagonista, després del seu periple vital per la Guerra Civil al Cinqué Regiment, les Brigades Internacionals i Socorro Rojo passa a França el febrer del 1938 per a viatjar després fins a Mèxic. També Asylum ens parla del viatge transcontinental d'una de les protagonistes, que salpà en el vaixell Cuba des de Le Havre el 24 de juny de 1939 cap al port de La Guaira, a Veneçuela, on arribà el 29 de juliol de 1939 amb 82 refugiats bascos a bord.

Acabem aquest apartat amb un apunt final sobre aquests relats, en els quals utilitzem amb certa lleugeresa la paraula "viatge" associada a l'exili. Marina, l'anciana protagonista d'Asylum, diu en dues vinyetes a la neta: «¡Naaaa! ¡Nada de viajes! ¡Eso suena a otra cosa, a turismo o algo así, y nadie se exilia por gusto! [...] Exiliarse es escapar, ¿Entiendes? Es... desgarrarse... perder lo más profundo, ¡tu propia vida!» (Isusi 2017, 14-15). 


\section{Còmics sobre la resistència a l'exili}

La resistència està retratada en referències breus en còmics que tracten temes contemporanis a la lluita armada i que no comentarem en detall, ${ }^{9}$ i també en els àlbums complets dedicats exclusivament al maquis o a les xarxes d'evasió. ${ }^{10}$ Molts dels exiliats que creuaren la frontera durant la retirada van incorporar-se com a voluntaris a la lluita contra el nazisme formant part de les tropes aliades o de la resistència francesa. Després, en sentenciar la derrota nazi, milers d'ells van formar part de la guerrilla antifranquista que va participar en l'Operació Reconquesta d'Espanya la tardor del 1944. Avortada eixa operació militar, part dels guerrillers supervivents actuaren a la Península principalment durant les dècades dels quaranta i cinquanta en agrupacions preexistents o en partides de noves agrupacions. Ja entrada la dècada dels seixanta, encara els últims guerrillers anarquistes van oposar resistència armada al règim. Les agrupacions, partides i grups més pròxims a la frontera van ser les que van continuar un incansable trajecte d'anada i tornada cap i des de França, des d'on es nodrien de propaganda, armes i nous guerrillers que vivien a l'exili.

Malauradament, la resistència protagonitzada pels maquis no és tan coneguda com altres aspectes de l'antifranquisme en temps de postguerra.

9 D’alguns en fem menció en altres apartats (El arte de volar, Los surcos del azar o El artefacto perverso); d'altres són Estraperlo y tranvía (2007), amb el maquis en plena missió des de les muntanyes de la frontera pirinenca fins a l'entorn urbà, i El solar (2016), d'Alfonso López, que arranca amb la sortida del camp de concentració d'un pres republicà. Mil vidas más (2010), d’Alfonso López, Pepe Gálvez i Joan Mundet, conta la vida del militant comunista Miguel Núñez, partícep de la guerrilla catalana. El pico de los cuervos: matar a Franco (2013), de Mikel Begoña i Iñaket, sobre el cas Granado i Delgado, inclou la mort de Ramon Vila Capdevila Caracremada, exiliat, combatent en la resistència; va ser l'últim maqui anarquista català abatut l'any 1963 a causa d'una emboscada de la Guàrdia Civil. En El ala rota (2016), d'Altarriba i Kim, hi ha una referència a la primera guerrilla. D'altra banda, podem esmentar El tresor d'en Lucio (2018), de Belatz, sobre la vida de l'anarquista Lucio Urtubia, exiliat a França en desertar de l'Exèrcit. També trobem breus referències sobre el tema en El hijo (2009), de Torrecillas i Alba, entre altres possibles títols.

10 No volem deixar de mencionar Los días rojos de la memoria (2014), d’Ana Penyas, més llibre illustrat que còmic, treball autoeditat on explica la peripècia de Longinos Lozano, enllaç de l'Agrupació Guerrillera de Llevant i Aragó (AGLA) que escapa, adquireix una identitat falsa i finalment fuig a França, on viurà exiliat des de l'any 1951 fins al 1977. També cal esmentar la historieta curta «Quico Sabaté: el expropiador justiciero", amb dibuixos de Marc Vila i guió de Rodrigo Vescovi, inclosa en el volum Bandidos generosos (2017). Hi trobem la història d'aquest mite de la guerrilla urbana anarquista, que preparava les accions des de l'altra part de la ratlla. 
Tampoc no compta amb una producció gràfica gaire nombrosa i són poques les referències trobades que se centren exclusivament en la lluita guerrillera, la qual és pràcticament insignificant dins del panorama editorial i de qualitat desigual.

\section{Frontera de Ordesa: red de evasión Ponzán (Juanerete \& Tapia 2020)}

Narra com el mestre anarquista d'Osca Francisco Ponzán, en traspassar la ratlla per Bourg-Madame i després d'eixir del camp de concentració de Vernet, organitza a la França ocupada pels nazis una potent xarxa d'evasió formada per militants llibertaris en collaboració amb els serveis secrets britànic i francès. El grup Ponzán i la xarxa Pat O’Leary ajudaren a escapar més de 3.000 persones per tot el sud de França. Ponzán va ser afusellat l'agost del 1944.

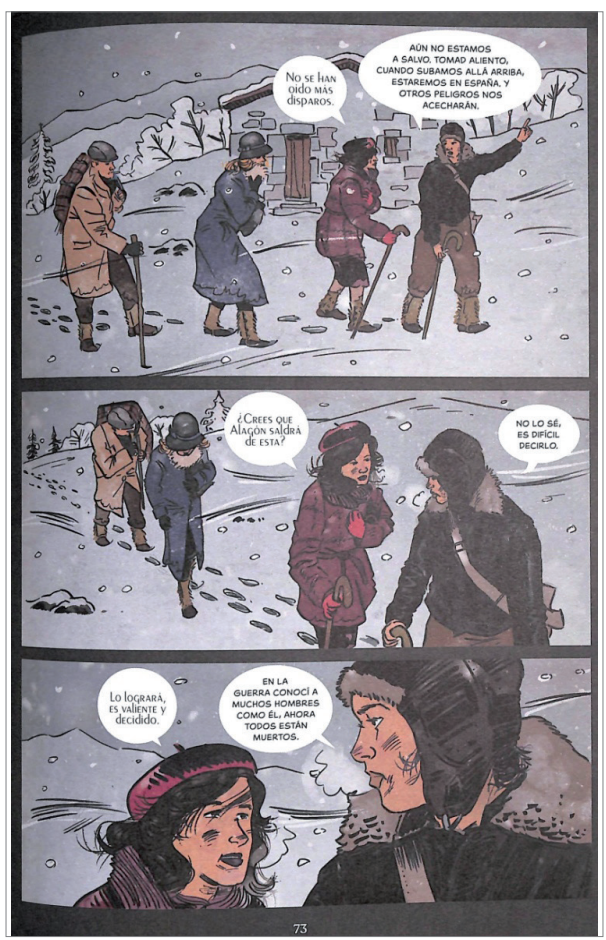

11 Frontera de Ordesa: red de evasión Ponzán

(Juanerete \& Tapia 2020) 
La primera part narra esdeveniments històrics que giren al voltant de la Segona República. En aquest segon volum els autors fan un salt en el temps i situen l'acció en la tardor del 1944. El còmic reflecteix dos aspectes prou importants: el primer és la collaboració dels combatents exiliats espanyols en la lluita per l'alliberament de França del nazisme, organitzats en les unitats de la resistència, i el segon l'important pla amb el nom de Reconquesta d'Espanya, ideat com una ofensiva per acabar amb Franco. Es tractava d'una operació en què es van desplegar uns 4.00o guerrillers (exiliats a França) per la Vall d'Aran i altres valls pirinenques que, tot i que fracassada, va donar lloc al rellançament de les agrupacions ja existents o a la creació d'altres de noves amb l'entrada de grups de guerrillers aïllats per diferents zones peninsulars.

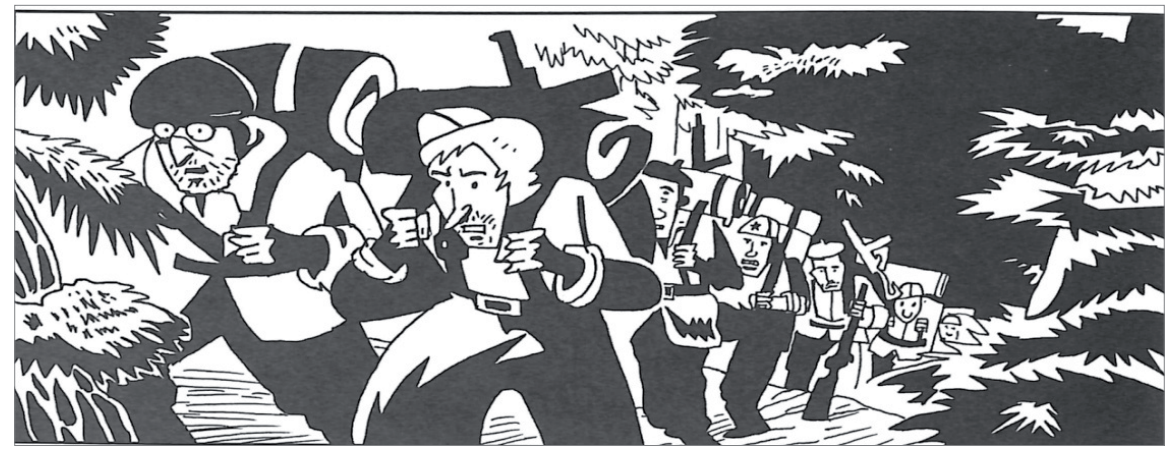

12 Primavera Tricolor 2: guerrilles de la Llibertat (Santamaría \& Farruco 2008).

\section{Sordo (Muñoz \& Pulido 2008)}

És una novella gràfica que ens remunta al 1942, any en què es posaran en marxa les primeres agrupacions guerrilleres. Amb un estil de dibuix que ens remet al cinema expressionista, amb un fort contrast de blancs i negres, la vinyeta teixeix una dramàtica història des del silenci i l'aïllament a través del maqui Anselmo, sord a causa d'un sabotatge fallit. El guerriller, perdut, sol, embogit, intenta per tots els mitjans escapar a França. 


\section{El Maquis (Escorihuela 2012)}

Segons l'autor, conta uns esdeveniments reals ocorreguts a Aragó a un guerriller, a qui anomena Manuel, des del 1936 fins al 1996, quan ja era jubilat a Alacant. En acabar la guerra, passa als camps de concentració de França, on sobreviu com pot durant tota l'ocupació alemanya. Després, sota les ordres del PCE, torna a Espanya com a guerriller de l'AGLA (Agrupació Guerrillera de Llevant i Aragó). L'acció se situa en terres de Terol, a la serralada Ibèrica; per això podem afirmar que el protagonista va haver d'actuar integrat en el sector 17 o 23 d'aquesta agrupació. Aquest guerriller torna a fugir, finalment, cap a l'exili, atrapat entre l'assetjament de la Guàrdia Civil i les tensions internes dels seus propis companys, $\mathrm{i}$ s'installa a França fins a la mort de Franco.

\section{El viaje a la luz (Barbero 2019)}

El viaxe a la lluz és el títol original en asturià. Les pàgines alternen el fons acolorit en diversos tons amb traços en negre i amb altres tonalitats en què el color de les vinyetes preval per explicar-nos un argument basat en les vivències ficcionades de la família materna de l'autor. La història transcorre durant la dècada dels cinquanta, amb els últims maquis assetjats per la Guàrdia Civil a la comarca asturiana de Ponga. Apareix, també, en un segon pla, el Mèxic de l'exili d'un dels personatges, que prèviament havia passat per França.

\section{Unes notes finals}

El còmic de l'exili segueix la línia cronològica i d'accions derivada de la derrota de la República. Hi trobem referències a les eixides massives de refugiats del 1937, si bé s'hi tracta majoritàriament la fugida de finals del 1938 i principis del 1939. Els esdeveniments successius que hi apareixen són la retirada, el pas a França, l'internament de la majoria dels republicans en els camps de concentració de les platges del Rosselló i d'altres departaments francesos i l'eixida dels camps per a tornar a Espanya, per a traslladarse a Amèrica o per a entrar a les companyies de treballadors estrangers 


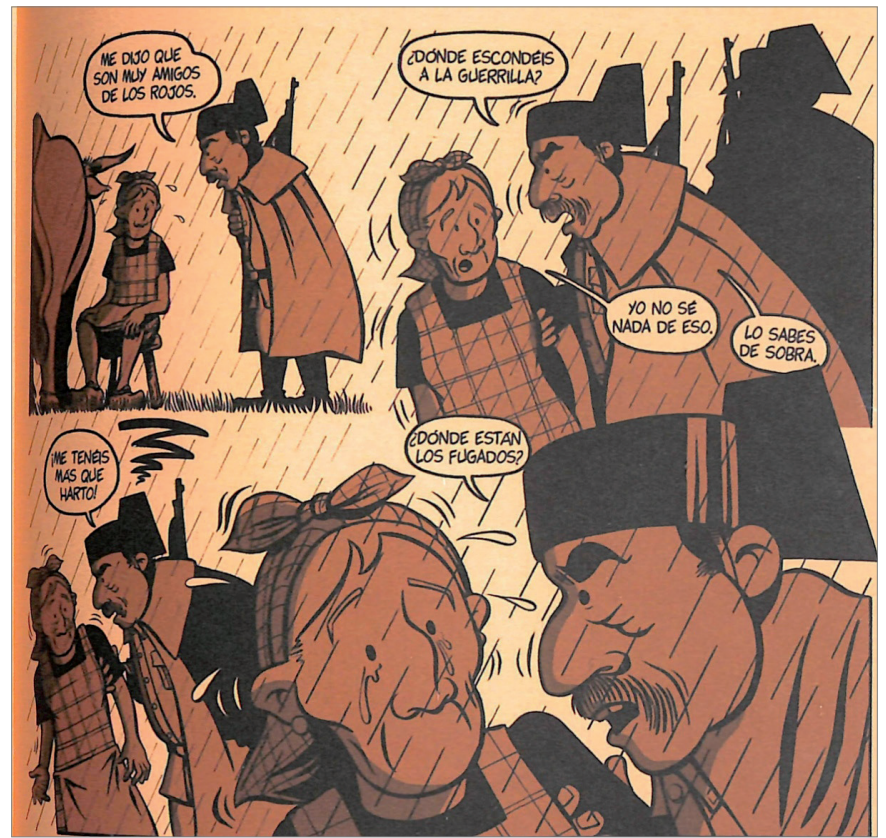

13 El viaje a la luz (Barbero 2019).

(CTE). Després podem llegir sobre l'esclat de la Segona Guerra Mundial, la resistència armada a França o a Espanya i el pas pels camps d'extermini nazis fins a l'alliberament o la mort. L'alliberament pot comportar, alhora, una segona diàspora més llunyana (majoritàriament a Amèrica però també als països europeus, del nord i de l'est, o al nord d'Àfrica), que esdevindrà exili permanent als països d'acollida, principalment a França.

Òbviament, en tractar-se de títols que omplen l'absència de tantes persones que hagueren de marxar, el conjunt d'obres mencionades dona veu als vençuts, als protagonistes de la derrota i de l'exili. El destí d'eixos milers de persones no es va tindre en compte mai en cap historieta ni durant el franquisme dins del país ni en eixos mateixos temps des de l'exili. Ha estat en acabar la dictadura quan d'una manera intermitent i irregular han anat aflorant aquestes obres que reivindiquen eixa memòria dels vençuts.

D'altra banda, es fa palesa la idea de correspondència entre l'exili republicà i tots els exilis posteriors o actuals. Es percep una intenció dels 
autors de pensar en altres exilis actuals al món, de conflictes anàlegs que signifiquen el mateix per a l'ésser humà. Paco Aura, a partir de la situació que es va viure als Balcans, fa una retrospecció fins a la seua guerra i exili, la del 1936, en Esperaré siempre tu regreso. És el mateix cas d'Asylum, en què els exilis tenen una perspectiva més coral i diversa però que fan recordar igualment l'exili dels bascos des del principi de la Guerra Civil.

Aquestes primeres característiques ens duen a veure com el còmic serveix per a recuperar la memòria collectiva i que transmet la preocupació de l'artista davant l'entorn social. Però, a més a més, el còmic ofereix una visió que va més enllà dels límits de la historiografia. El factor humà de la narració dibuixada va lligada als records familiars i a la quotidianitat de la tragèdia. Els relats, considerats per alguns estudiosos exponents de la postmemòria (Quílez 2014), naixen d'experiències individuals o de testimonis recollits. Els esdeveniments històrics són viscuts a través de l'experiència individual, amb totes les conseqüències que això puga tenir en el desenvolupament de la narració. És el cas d'Un largo silencio i d'El arte de volar, darrere les vinyetes dels quals hi ha la vida d'una família relacionada amb el dibuixant.

Els autors pertanyen a generacions que no van viure en primera persona els fets retratats. Recreen la història dels seus protagonistes des de la distància, des de la documentació i l'estudi de fets, llocs i personatges. La motivació dels autors és la necessitat de recuperar la memòria i de traslladar-la a una vinyeta, perquè cada vegada queden menys persones vives que puguen transmetre-la. Malgrat això, en alguns còmics el relat es construeix des de les veus dels mateixos protagonistes, que, a més, són majoritàriament homes. De fet, Un largo silencio, El arte de volar i Días rojos de la memòria illustren les memòries manuscrites dels protagonistes. En El tresor d'en Lucio, Belatz s'ha basat en les múltiples entrevistes personals que va mantenir durant mesos amb Lucio Urtubia, i en El Maquis l'autor deixa entreveure que el còmic és producte de relats i converses mantingudes amb el protagonista. En Los surcos del azar Roca recrea unes suposades entrevistes de qui serà el protagonista de la història. En molts casos, a més de la distància dels autors, aliens als fets narrats, i la subjectivitat de les fonts directes, cal afegir-hi la fragilitat de la memòria. No obstant això, inconscientment i seguint la pretensió dels autors, com a lectors 
donem legitimitat i veracitat al que ens relaten amb imatges, textos $i$ altres elements paratextuals.

Precisament, un element recurrent en molts d'aquests còmics és l'ús dels paratextos (conjunt d'enunciats que acompanyen el text principal d'una obra) com a reivindicació de la memòria, de les absències, de les mentides i dels pactes de silenci. Encara que és literatura dibuixada, molts còmics sovint contenen paratextos que intenten explicar que no hi ha cap invenció en l'univers diegètic. En una nota dels crèdits d'Asylum, per exemple, podem llegir: «La mayor parte de las historias narradas en Asylum se basan en hechos reales. Para proteger la privacidad de las personas hemos cambiado su nombre» (Isusi 2017, 4). Així, trobem material complementari a la major part de les obres citades en forma d'introduccions, pròlegs, sinopsis, fragments de guió, disseny de personatges, documentació, fotografies d'època i, fins i tot, relats autobiogràfics; també inclouen entrevistes als autors o als protagonistes, vocabularis, cronologies, poemes i cançons. I és que «la memoria se recompone de retazos, esos elementos también pueden verse como piezas que contribuyen a la formación de un mosaico y su función ética y estética en la narrativa se inserta en la estructura misma de la obra» (Rodrigues 2020, 287).

Un exemple paradigmàtic és El fotógrafo de Mauthausen, amb més de cinquanta pàgines de material documental divers. També Peidro afegeix a Esperaré siempre tu regreso uns «contenidos adicionales» (2016, 193-200), en el qual veiem que la figura real que inspira el llibre és la del deportat d'Alcoi Paco Aura. O la nova edició de Sordo, amb contingut extra que inclou la sinopsi, fragments de guió, disseny de personatges i altres textos i material gràfic. Són elements que remarquen constantment la versemblança de la història, una base ben real per la documentació emprada. Els paratextos subratllen la versemblança del que es narra, la implicació històrica del que s'explica amb una tècnica gràfica que també contribuirà a ressaltarho. Com estudia de manera molt completa Fernández de Arriba (2018), el còmic és un mitjà per a recuperar històries i memòria i una arma potent per a treballar la memòria històrica, per exemple, a l'aula escolar.

Altres obres amb material complementari són, per exemple, Frontera de Ordesa, Primavera tricolor 2: guerrilles de la Llibertat, Sol poniente, Un largo silencio - en la qual destaquen deu planes de fotos familiars 
i documents administratius- o El pico de los cuervos, amb un complet dossier amb retalls de premsa, fotografies i diàlegs. Aquesta característica comuna de presentar tantes fonts informatives, textos i imatges respon a l'intent de mostrar al públic lector uns relats imbuïts d'una legitimitat documental que els aproxime a la veracitat. Uns altres dos casos especials són el catàleg Diario de ruta sobre l'exposició de Los surcos del azar que va realitzar l'Ajuntament de València a Las Naves l'any 2014; la guia didàctica El arte de volar: instrucciones de uso, d'Antoni Guiral, o el treball final de grau d'Ana Penyas, en què explicava el procés gràfic i d'investigació que hi havia darrere de Días rojos de la memoria.

Com passa en la narrativa, també veiem que hi ha un compromís personal dels autors, siguen guionistes, siguen dibuixants, amb la memòria dels vençuts. En són un exemple Agustín Comotto, Juan Kalvellido, Felipe Hernández Cava, Pepe Gálvez, Ana Penyas, Antonio Altarriba o Rodrigo Vescovi, i ho podem fer extensiu a molts altres autors referenciats en l'article.

Aquest compromís o interès social ve lligat de vegades amb el mateix editor. Així, per exemple, Exilio, de Juan Kalvellido, és publicat per l'editorial de pensament d'esquerres El Viejo Topo amb l'Associació de Terrassa per la Tercera República i el Memorial Democràtic de la Generalitat de Catalunya. Asylum destina tots els seus beneficis a l'ONG CEAR-Euskadi. Primavera tricolor 2: guerrilles de la Llibertat està editat per la Fundació Pere Ardiaca, vinculada al Partit Socialista Unificat de Catalunya (PSUC), mentor ideològic de l'agrupació guerrillera protagonista del relat. «Quico Sabaté: el expropiador justiciero» és publicat per l'editorial de signe anarquista Descontrol. El tresor d'en Lucio és coeditat per Txalaparta i Tigres de Paper, dos segells amb una línia editorial ideològicament compromesa.

Per a mostrar la veracitat del relat sovint es recorre a persones reals que poden ser o no els mateixos protagonistes que conten la seua vida bé directament, bé a través de memòries, entrevistes o investigacions, com acabem de veure. Persones reals com Amado Granell (Los surcos del azar), Alejandro Finisterre (Futbolín), Longinos Lozano (Los días rojos de la memoria), Francisco Gallardo (Un largo silencio), Antonio Altarriba (El arte de volar), Francisco Sabaté Llopart El Quico (El tresor d'en Lucio, El solar, Estraperlo y tranvía, «Quico Sabaté: el expropiador justiciero»), Francesc Boix (El fotógrafo de Mauthausen), Paco Aura (Esperaré siempre 
tu regreso), Lucio Urtubia (El tresor d'en Lucio), Simón Radowitzky (155. Simón Radowitzky), Antonio Hernández Marín (Deportado 4443), Ramon Vila Capdevila Caracremada (El pico de los cuervos), Francisco Ponzán (Frontera de Ordesa) o Tina Modotti (Tina Modotti. Una mujer del siglo XX). N'hi ha d'altres dels quals, tot i no conèixer-ne la identitat, els autors ens informen que estan basats en persones que van existir. Els protagonistes dels relats - siguen persones reals, anònimes o ficcionades - responen majoritàriament a un perfil humà allunyat del mite i en alguns casos més pròxims, si més no, a la figura de l'antiheroi. La presència d'un personatge principal no trau, però, que el protagonisme siga del conjunt de persones expulsades a la força del país, que esdevenen, potser, un mite collectiu.

Un altre element utilitzat per donar valor historiogràfic al relat és emmarcar-lo en les dates reals en què van succeir els fets descrits. Així, si ens parem a analitzar aquelles bafarades que daten qualsevol acció, vorem com citen la data més aproximada, fins i tot exacta, d'allò narrat: el pas per la frontera, la sortida d'un vaixell, l'internament en un camp de concentració, l'ingrés a la guerrilla, la tornada a Espanya, etc. També trobem, però, alguna errada cronològica (Asylum, Sordo) que, tanmateix, no desmereix el conjunt del relat i el seu context històric.

Lligat a la datació, i amb el mateix desig de donar versemblança a la història, també trobem el tret de situar l'acció en els escenaris reals dels fets. Ho podem veure a través de les bafarades, en els diàlegs dels protagonistes, en els dibuixos amb rètols que nomenen una localitat o un país i en l'ús de mapes que poden estar inclosos bé en la mateixa narració gràfica, bé com a elements paratextuals (Los surcos del azar, La Guerra Civil española, Los dias rojos de la memoria).

Un altre element destacable és el valor documental de la fotografia. Com hem comentat adés, per tal de documentar les històries els autors han utilitzat imatges icòniques àmpliament conegudes i difoses. Hi trobem imatges de reconeguts fotògrafs, majorment reporters de guerra, moltes publicades a la premsa internacional de l'època per agències, diaris i setmanaris illustrats (Paris Match, L'Illustré, Photo, France Presse, SAFARA - Service des Agences Françaises d'Actualités et de Reportages Associés-, Fulgur, The New York Times, Keystone, Associated Press Photo o ACME). En l'apartat sobre la retirada en els còmics mencionats hi veiem reflectides 
en illustració i dibuix fotografies preses per Robert Capa de civils cap a la frontera, d'August Chauvin en les corrues de gent al mateix pas fronterer del Pertús, de David Seymour Chim i moltes d'altres d'autoria anònima. Amb tot plegat es reforça la idea de la composició de mosaic narratiu, tal com ha assenyalat Rodríguez (2020).

Succeeix el mateix en els còmics centrats en els camps de concentració i d'extermini, amb imatges, de nou, de Robert Capa (de les platges d'Argelers a la mateixa portada d'Exilio), d'Agustí Centelles (cabanyes, barracons, filats, tropes colonials o gendarmes del camp de Bram), de l'oficial alemany Paul Ricken i del mateix protagonista d'El fotógrafo de Mauthausen, Francesc Boix, al camp, així com d'altres fotoperiodistes i arxius gràfics d'associacions i institucions (presoners, installacions, ajusticiaments, forns crematoris, la cantera, filferrades a Deportado 4443). Del tercer bloc, la diàspora d'ultramar, veiem com el dibuix trasllada a la vinyeta la imatge fotogràfica de premsa dels vaixells i els seus passatgers durant la travessia, amb naus com Mexique, Habana, Cuba, Stanbrook, Winnipeg o Djebel Amour. I, finalment, dels còmics que fan referència a la resistència — siga amb forces aliades, siga a la resistència francesa o els maquis-, també n'hem rastrejat fotografies històriques, com l'entrada dels blindats de la divisió Leclerc a París en Los surcos del azar, o la fotografia de premsa del maqui Caracremada mort a El pico de los cuervos, on també apareixen les imatges de la seua fitxa policial.

Finalment, hi ha alguns títols que recullen bona part del cicle de l'exili segons les categories en què hem dividit aquest treball (retirada, camps de concentració, diàspora d'ultramar i resistència): El arte de volar, Un largo silencio, Esperaré siempre tu regreso, 'Winnipeg', 155. Simón Radowitzy o Los surcos del azar.

Les conseqüències de la guerra d'Espanya i l'exili de milers de persones entra al còmic segons l'interès dels autors per recuperar el temps perdut. Siga un relat realista, metafòric o fins i tot fantàstic, el còmic representa uns esdeveniments que han causat traumes individuals i collectius, compartits per una memòria narrativa. Igual que ha fet la literatura, la pintura o el cinema, el còmic ha mostrat la seua força subversiva en plantejar dubtes quan destapa qüestions amagades pel pes del silenci. La historieta té la possibilitat d'aconseguir un públic lector més ampli i, per tant, és idònia 
per a la reflexió sobre determinats fets històrics, processos traumàtics o temes socials.

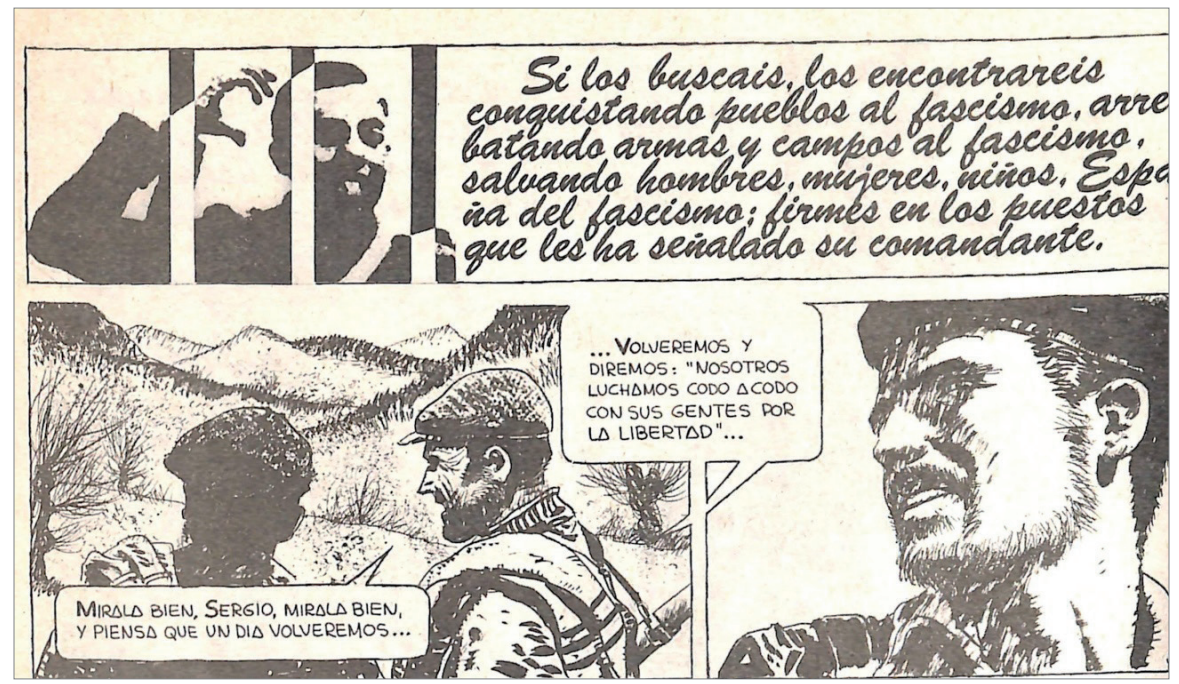

14 Si los buscáis (Hernández Cava \& Marzal 1977).

\section{Bibliografia}

Alary, Viviane. 2016. «La Guerra Civil española vista». Diablotexto Digital 1: 6-28. doi: https://doi.org/10.7203/diablotexto.1.8911.

- 2020. «La bande dessinée contemporaine au rendez-vous de la mémoire violente de l'après-guerre civile espagnole et du premier franquisme». Cahiers de civilisation espagnole contemporaine 24 (13 juliol). doi: https://doi.org/10.400o/ ccec.9342.

- 2020. «Postfacio. De la utilidad de la historieta para indagar en la memoria de la Guerra Civil». Dins Viviane Alary i Michel Matly, ed., Narrativa gráfica de la Guerra Civil, 353-371. Lleó: Universidad de León / Eolas Ediciones.

Alcantarilla Hidalgo, Fernando J. 2017. El siglo xx en viñetas. Barbarie y humanismo en el cómic europeo. Barcelona: Coeditum.

Alsina, Jean. 2002. «La narración en El artefacto perverso. Algunas calas en un objeto inagotable». Dins Viviane Alary, ed., Historietas, cómics y tebeos españoles, 210-227. Toulouse: Presses Universitaires du Mirail.

Fernández de Arriba, David. 2015. «La memoria del exilio a través del cómic. Un largo silencio, El arte de volar y Los surcos del azar». CuCo, Cuadernos de cómic 4: 7-33. 
Fernández de Arriba, David. 2018. Memòria i vinyetes: La memòria històrica a l'aula a través del còmic. Barcelona: Memorial Democràtic de la Generalitat de Catalunya.

Guiral, Antoni. 2012. El arte de volar: instrucciones de uso. Alacant: Edicions de Ponent.

Matly, Michel. 2018. El cómic sobre la Guerra Civil. Madrid: Cátedra.

- 2020. «La representación de la Guerra Civil española en el cómic, entre provocación, legitimidad y polémica». Dins Viviane Alary i Michel Matly ed., Narrativa gráfica de la Guerra Civil, 25-41. Lleó: Universidad de León / Eolas Ediciones.

Merino, Ana, i Brittany Tullis. 2013. «The Sequential Art of Memory: The Testimonial Struggle of Comics in Spain Memory and Its Discontents: Spanish Culture in the Early Twenty-First Century». Hispanic Issues On Line 11: 211-225.

Piedras Monroy, Pedro. 2017. «Recuerdos, emoción, representación. Formas de la memoria de la represión en la España actual». Studia Romanica Posnaniensia 44 (1): 63-73. doi: https://doi.org/10.14746/strop.2017.441.005.

Quílez Esteve, Laia. 2014. «Hacia una teoría de la posmemoria. Reflexiones en torno a las representaciones de la memoria generacional». Historiografias 8 (juliol-desembre): $57-75$.

Roca, Paco. 2014. Los surcos del azar: Diario de ruta de Paco Roca. València: Ajuntament de València.

Rodrigues Martín, Iván. 2020. «Mosaico narrativo: la Guerra Civil española y el franquismo». Dins Viviane Alary i Michel Matly, ed., Narrativa gráfica de la Guerra Civil, 265-293. Lleó: Universidad de León / Eolas Ediciones.

\section{Còmics referenciats}

Ávila, José Antonio, i Mariano Viñuales. 2013. Blanquito. Nota preliminar de Carmen Cañete Quesada. Saragossa: GP Ediciones, 96 p.

Alonso García, Jorge. 1987. La Guerra Civil en España, 1936-1939. Granada: Genil, 160 p. Altarriba, Antonio, i Kim [Joaquim Aubert Puigarnau]. 2009. El arte de volar. Alacant: Edicions de Ponent, 206 p.

- L'art de volar. 2012. Barcelona: Editores de Tebeos, 208 p.

- 2016. El ala rota. Barcelona: Norma Editorial, 262 p.

Artís-Gener, Avellí. 1977. Història en historieta de Catalunya. Barcelona: Edhasa, 168 p. Bayés, Pilarín, Josep M. Solé i Queralt Solé. 2014. Història de Catalunya. De la prehistòria als nostres dies. Barcelona: Edicions 62.

Belatz [Mikel Santos]. 2018. El tesoro de Lucio: Una novela gráfica sobre la vida de Lucio Urtubia. S. l.: Txalaparta, 138 p.

- 2018. Gerezi garaia: Lucio Urtubarien biografia ilustratua. S. 1.: Txalaparta, 138 p.

- 2018. O tesouro de Lucio: vida de Lucio Urtubia. S. 1.: Demo, 138 p.

- 2018. El tresor d'en Lucio: una novella gràfica sobre la vida de Lucio Urtubia. S. 1.: Tigre de Paper, 138 p.

Barbero, Ruma. 2019. El viaje a la luz. Alcalá de Henares: Ediciones Marmotilla, 128 p. 
Begoña Garaizar, Mikel, i Iñaket [Iñaki Martínez Fernández]. 2013. El pico de los cuervos: matar a Franco. Barcelona: Norma Editorial, 126 p.

Bergès Saura, Miquel À., i Cazares [Josep M. Cazares]. 2006. 1936: memòria d’un estiu. Lleida: Ajuntament / Pagès editor, 58 p.

Bou, Quim, i Ponsatí, Rafel. 2007. Josep Irla. La lluita per un ideal. Barcelona: Diari Avui, $32 \mathrm{p}$.

Cabezas, Octavio, Manel Berrocal i Juan C. Martín. 1982. Historia del socialismo español. Barcelona: Cómic-MAM, 48 p.

Carbos [Antonio Carrillo Bosch], i Javier Cosnava [Javier Costa Navarro]. 2011. Prisionero en Mauthausen (Un análisis de la culpa personal y colectiva). Pròleg de Rosa Torán. Alacant: Edicions de Ponent, 104 p.

Cosnava, Javier [Javier Costa Navarro], i Rubén del Rincón. 2014. Las damas de la peste. Madrid: Dibbuks, 99 p.

Cosnava, Javier [Javier Costa Navarro], Fernandó Baldó, Toni Carbos, Javier N. B., Sofía Espinosa, Bernardo Muñoz, Dani Acuña i Alfonso Zapico. 2009. Un buen hombre. Barcelona: Glénat, 77 p.

Colombo, Pedro J., Salva Rubio i Aintzane Landa. 2018. El fotógrafo de Mauthausen [Le photographe de Mathausen]. Barcelona: Norma Editorial, 168 p.

Comotto, Agustín. 2018. 155. Simón Radowitzky. Barcelona: Nórdica Cómic, 270 p.

Dounovetz, Serguei, i Paco Roca. 2010. El ángel de la retirada. Nota històrica d'AnneMarie Sabatier. Barcelona: Bang Ediciones, 58 p.

De la Calle, Ángel. 2019. Modotti. Una mujer del siglo XX. Pròleg de Paco Ignacio Taibo II. Madrid: Reino de Cordelia, 316 p.

Ferrada, María José, i Ana Penyas. 2017. 'Mexique': el nombre del barco. Madrid: Libros del Zorro Rojo, 32 p.

Forges [Antonio Fraguas]. 1984. Historia forgesporánea. Barcelona: Zinco-Procómic.

Fritz [Ricardo Olivera]. 2006. «Mi tío, que estuvo en el infierno». Nuestra guerra civil, 29-38. Còrdova: Ariadna Editorial.

Gallardo Sarmiento, Francisco, i Miguel Gallardo. 1997. Un llarg silenci. Traducció de Paco Camarasa. Alacant: Edicions de Ponent, 64 p.

- 2012. Un largo silencio. Bilbao: Astiberri Ediciones, $72 \mathrm{p}$.

Gálvez, Pepe, i Joan Mundet. 2010. Mil vidas más: Miguel Núñez. Alacant: Edicions de Ponent, $100 \mathrm{p}$.

García, Jorge i Miguel A. Díez. 2003. «Vías muertas». Dos veces breve 1:12-15.

- 2003. «Fuegos del fin del mundo». Dos veces breve 5: 12-15.

Gibson, Ian, i Quique Palomo. 2019. Ligero de equipaje: vida de Antonio Machado. Barcelona: Penguin Random House / Ediciones B, 104 p.

Giménez, Carlos. 2011. 36-39: malos tiempos. Barcelona: Glénat / De Bolsillo, 384 p. Juanerete [Juan Pérez] i David Tapia. 2020. Frontera de Ordesa: red de evasión Ponzán. Saragossa: GP Ediciones, 92 p.

Hernández Cava, Felipe, i Jaime Marzal. 1977. «Si los buscáis». Bang!, Extra Trocha 1: $27-31$. 
Hernández Cava, Felipe, Federico Barrio Jiménez i Raúl Fernández. 1991. «Noches de agua». Los derechos del niño, 61-70. Vitòria: Ayuntamiento de Vitoria-Gasteiz / Ikusager.

Hernández Cava, Felipe, i Federico Barrio Jiménez. 1996. El artefacto perverso. Prefaci i pròleg de M. Vázquez Montalbán. Barcelona: Planeta DeAgostini, 64 p. ${ }^{11}$

- 2015. El artefacto perverso. 2a ed. Pròleg de Felipe Hernández Cava. Barcelona: ECC Ediciones, $64 \mathrm{p}$.

Hernández Cava, Felipe, i Bartolomé Seguí. 2008. Las serpientes ciegas. Barcelona: Norma Editorial, 72 p.

- 2010. Les serps cegues. Barcelona: Inrevés Edicions, 72 p.

Hernández de Miguel, Carlos, i Ioannis Ensis. 2017. Deportado 4443: sus tuits ilustrados (La historia de los 9.30o españoles cautivos en campos de concentración). Barcelona: Ediciones B, $262 \mathrm{p}$.

Hill, Cecília, i Josep Salvia. 2019. Antonio Machado. Los días azules. Prefacis de V. Sierra, M. Barrero, J. Salvia i C. Hill. Madrid: Diábolo Ediciones, 128 p.

Isusi, Javier de. 2017. Asylum. Bilbao: Astiberri, 104 p.

Jiménez, Rafael, Kaskajo [José Miguel Castro] i María Pedrosa. 2018. 1937: los niños de la guerra. Sevilla: Asociación Juvenil Carmona en Viñetas, 28 p.

Juste de Nin, Lluís. 2015. Quan de tu s'allunya. De l'ocupació de París a la caça de bruixes. Alacant: Edicions de Ponent, 187 p.

Kalvellido, Juan, Salvador Pujol i Miquel Piera. 2011. Exilio. Repàs històric de Manel Márquez. Barcelona: Associació de Terrassa per la Tercera República / El Viejo Topo, $52 \mathrm{p}$.

- 2011. Exili. Repàs històric de Manel Márquez. Barcelona: Associació de Terrassa per la Tercera República / El Viejo Topo, 52 p.

Llobell, Sento. 2017. Doctor Uriel. Bilbao: Astiberri, 432 p.

López, Alfonso. 2007. Estraperlo y tranvía. Barcelona: Ediciones B, 48 p.

- 2016. El solar. Barcelona: La Cúpula, 106 p.

López Cruces, Joaquín, i María Isabel Santisteban. 2015. Sol poniente. Alacant: Edicions de Ponent, $85 \mathrm{p}$.

Martel, Laura, i Antonia Santoloya. 2014. 'Winnipeg': el barco de Neruda. Madrid: Hotel de Papel, 84 p.

Muñoz, David, i Rayco Pulido. 2008. Sordo. Alacant: Edicions de Ponent, 69 p.

- 2018. Sordo. 2a ed. Bilbao: Astiberri, 81 p.

Migoya, [Hernán], Perro [Carlos García], [José María] Beroy, [Joan] Marín i [Daniel] Acuña. 2011. Dos águilas de un tiro. Collecció «Nuevas Hazañas Bélicas. Serie Roja», vol. 1. Barcelona: Glénat.

Migoya, Hernán, Miquel Fuster i Daniel Acuña. 2012. ¡Animales de campo! El sufrimiento de los presos republicanos en Francia. Collecció «Nuevas Hazañas Bélicas. Serie Roja», vol. 14. Barcelona: Glénat / EDT / Norma Editorial.

11 Els cinc capítols es publicaren prèviament en 1994 del sisè al desè número de la revista Top Cómics (Ediciones B). 
Peidro, Jordi. 2016. Esperaré siempre tu regreso. València: Desfiladero Ediciones, 200 p. Penyas, Ana. 2014. Los días rojos de la memoria. València: autoedició, 33 p.

Pérez Navarro, Francesc, i Jan [Juan López Fernández]. 2008 [1978]. Nosaltres, els catalans. Barcelona: Glénat, 68 p.

Preston, Paul, i José Pablo García. 2016. La Guerra Civil española. Madrid: Debate, 240 p. Roca, Paco. 2005. Le phare. Frontignan (Hérault): 6 Pieds sous Terre.

- 2013. Los surcos del azar. Bilbao: Astiberri, 328 p.

- 2014. El faro. Pròleg d'Enrique Luzuriaga Martín. Bilbao: Astiberri, 64 p.

Santamaría, Carles, i Pepe Farruqo. 2008. Primavera tricolor 2: guerrilles de la Llibertat. Pròleg de Josep Fontana. Barcelona: Fundació Pere Ardiaca, 8 o p.

Sanz Escorihuela, Juan. 2012. El Maquis. Madrid: Actas, 48 p.

Soler Amigó, Joan, Anna Duran Armengol, Josep M. Pujol i C. de B. Beaumont. 1989. Història de Catalunya. La Guerra Civil, la repressió i l'exili. Vol. 17. Barcelona: Junior, $42 \mathrm{p}$.

Torrecillas, Mario, i Tyto Alba. 2009. El hijo. Pròleg d'Agustí Villaronga. Barcelona: Glénat, 160 p.

Torres, Daniel. 2018. Picasso en la Guerra Civil. Barcelona: Norma Editorial, 148 p.

Vescovi Parrilla, Rodrigo, i Marc Vila. 2016. «Quico Sabaté: el expropiador justiciero». Bandidos generosos, 109-136. Barcelona: Descontrol. 
